\title{
Coupled wave and surge modelling for the eastern Irish Sea and implications for model wind-stress \\ Jennifer M. Brown ${ }^{\text {a,* }}$, Judith Wolf ${ }^{\text {a }}$
}

${ }^{a}$ Proudman Oceanographic Laboratory, Joseph Proudman Building, 6 Brownlow Street, Liverpool, L3 5DA, UK.

* Corresponding author Phone: +44 (0) 151795 4971, Fax: +44 (0) 151795 4801, Email: jebro@pol.ac.uk (J.M. Brown)

\begin{abstract}
We revisit the surge of November 1977, a storm event which caused damage on the Sefton coast in NW England. A hindcast has been made with a coupled surge-tidewave model, to investigate the effects of waves on the surge generation by modifying the surface drag. The POLCOMS-WAM modelling system has been used to model combined tides, surges, waves and wave-current interaction in the Irish Sea on a $1.85 \mathrm{~km}$ grid. This period has been previously thoroughly studied e.g. Jones and Davies (1998) and has been chosen here to validate the POLCOMS-WAM model to test the accuracy of surge elevation predictions in the study area. A one-way nested approach has been set up. It was demonstrated that (as expected) swell from the North Atlantic does not have a significant impact in the eastern Irish Sea. To capture the external surge generated outside of the Irish Sea a $\left(1 / 9^{\circ}\right.$ by $\left.1 / 6^{\circ}\right)$ model extending beyond the continental shelf edge was run using the POLCOMS model for tide and surge.
\end{abstract}

The model results were compared with tide gauge observations around the eastern Irish Sea. The model was tested with different wind-stress formulations including Smith and Banke (1975) and Charnock (1955). It has been demonstrated that Smith and Banke can be well-approximated by a constant Charnock parameter, but this varies with location. In order to get a single parameterisation that works with wavecoupling the wave-derived surface roughness length has been imposed in the surge model. One of the largest surge events that occurred at Liverpool in the last 10 years, in January 2007, has also been simulated to validate this model set up to demonstrate its robust application in the Liverpool Bay area.

Keywords: Wave-tide-surge modelling, Wave-current interaction; Surface windstress, POLCOMS, WAM, Liverpool Bay.

\section{Introduction}

Surges in UK waters are generally caused by strong winds due to mid-latitude depressions passing over the UK from the Atlantic. Currents in the sea are accelerated due to variations in the atmospheric pressure gradient and also as a result of wind-stress (Gill, 1982). Wind-stress generates flow perpendicular to the forcing stress as a result of Ekman dynamics. When this Ekman flow is towards the coast, water piles up, increasing the mean water level. Around the UK the surge typically behaves as a forced Kelvin wave (Gill, 1982), travelling anti-clockwise around a semi-enclosed sea, with the coast on the right.

Lennon (1963) suggested that major west coast storm surges are caused by Atlantic secondary depressions passing from SW to NE over the northern part of the British Isles at a critical speed of about 40 knots. Thus the spatial and temporal scales of 
these surges are smaller than those experienced in the North Sea. The wind-stress is most effective at producing a surface elevation gradient in shallow water. Depths in the eastern Irish Sea are only about $40 \mathrm{~m}$ on average and thus this area is prone to large surges which may cause flooding in low-lying coastal areas. Local surge generation in the eastern Irish Sea results from a simple force balance due to the surge-generating winds being predominantly from the $\mathrm{W}$ and $\mathrm{NW}$ and the simple geometry of the coastline (see Figs. 1 and 2) but the external surge is also important i.e. surge generation in the southern Irish Sea, Celtic Sea and SW Approaches (Jones and Davies, 1998).

Large surges at Liverpool can be up to 2.5m: one example is the November 1977 surge which was almost $2 \mathrm{~m}$ at Liverpool (Wolf, 2008). For the purpose of coastal flooding it is the maximum of total water level which is important. The maximum tidal range at Liverpool exceeds $10 \mathrm{~m}$ and thus dominates in terms of the timing of the peak of total water level; however the maximum surge residual at Liverpool generally does not fall on high water due to tide-surge interaction (Woodworth and Blackman, 2002).

During the night of 11 th and 12th November 1977 a severe storm coinciding with tidal high water overtopped coastal defences throughout Lancashire and Cumbria. Simulations of the November 1977 surge event (Davies and Jones, 1998) show that for surges in Liverpool Bay the flow into the Irish Sea through the North Channel and Celtic Sea (the external surge) is about equally as important as the locally generated surge. In the January 2007 event the maximum surge in Liverpool reached $2.23 \mathrm{~m}$. This is the second largest surge event in the last 10 years. The largest reached $2.6 \mathrm{~m}$ on the $27^{\text {th }}$ October 2002, but no wave data were recorded and there are limited surge data due to gauge failure. Liverpool Bay is sheltered from swell waves from the Atlantic and experiences locally wind-generated sea. Waves have been recorded in Liverpool Bay from November 2002 to the present (Wolf, 2008). The wave height typically exceeds $3 \mathrm{~m}$ during 5-10 events per year and exceeds $4 \mathrm{~m}$ from 1-5 times per year. The largest waves and surges in Liverpool Bay are generated by westerly and north-westerly winds which have the longest fetch.

Wave conditions may also be critical to coastal flooding, through overtopping of sea defences and low-lying areas. Wind waves are the mechanism through which the wind-stress interacts with the sea surface. When wind blows over the sea wind waves immediately start to grow, increasing in period and height with time, and also a mean flow is generated. These effects are linked with turbulent processes in the air and water boundary layers. Bulk parameterisations of the surface drag implicitly take account of the effect of waves (as drag increases with wind speed) but local conditions may mean that waves are not in equilibrium with the wind so it is of interest to model surge and waves simultaneously and examine their interactions.

In surge models the Smith and Banke (1975) formula (S\&B) is frequently used to parameterise the wind-stress, but this formula has been found to under-predict the surge conditions in the southern North Sea (Mastenbroek et al. 1993; Williams and Flather, 2000). Williams and Flather (2000) found it necessary to enhance the wind by a factor of 1.1 (equivalent to replacing $U_{10}$ by $U_{25}$ ) to get good surge forecasts. This may be related to the spatial model resolution in that the surge generation in shallow areas is poorly represented. The Charnock (1955) relationship is an 
alternative formula, which is used in the operational surge model at Proudman Oceanographic Laboratory (CS3). Janssen (1989, 1991, 2004), Janssen et al. (2004) and Mastenbroek et al. (1993) have all investigated representing the surface stress in the presence of waves by a Charnock-like method in place of S\&B. Mastenbroek et al. (1993) studied the effect of using the wave stress in a coupled wave-current model compared to using S\&B in a surge model. They found it performed well for young and old seas compared to S\&B. By using a Charnock relationship with $\alpha=0.032$ in a surge model they could reproduce the effects of using a coupled wave-surge model. Using a constant Charnock value in the surge model allows the stress to be tuned to obtain the desired surge levels at a particular location. However the optimum value may vary with location. It is thought the Charnock parameter is related to wave-age (Drennan et al., 2005). Here we aim to (i) use a consistent surface stress computation for wave and surge model and (ii) replace the constant value Charnock parameter with a wave-dependent parameter such that a global representation of the surface stress is obtained, without the need for tuning. Ideally we would like to use the same windstress in the surge and wave models (Mastenbroek, et al., 1993).

We use the Proudman Oceanographic Laboratory Coastal Modelling System (POLCOMS) as the surge model and the $3^{\text {rd }}$-generation spectral Wave Model (WAM). The November 1977 and January 2007 storm surge events have been used to study surge prediction in the eastern Irish Sea using both a coupled wave-tide-surge (POLCOMS-WAM) model and a tide-surge (POLCOMS) model. These two hindcast events have been simulated, to (i) investigate the effects of waves on the surge generation by modifying the surface drag and (ii) optimise the Charnock parameter without waves for the eastern Irish Sea. We modify POLCOMS such that a consistent formulation to WAM is applied for stress, which also facilitates coupling of the wave and surge models. A set of metrics for testing the models goodness of fit have been designed. We have tested the model set up by implementing various stress formulations in the POLCOMS model. The model set up and hindcast events are presented in section 2. The surge predictions are shown in section 3. Different coupled and uncoupled methods were tried to represent the surface stress in POLCOMS to best simulate the surge residuals at coastal tide gauges. The findings are discussed in section 4 with the focus mainly on Liverpool Bay. We conclude in section 5 that it is important to retain the wave-age dependence of the wave model via the Charnock parameter to produce appropriate stress for storm surges in Liverpool Bay, when using POLCOMS-WAM. A problem in the implementation of the wave stress in WAM for limited fetch and shallow seas has come to light, which does not occur for much larger wave-ages e.g. global WAM applications.

\section{Method}

\subsection{Model set up}

In order to accurately simulate the waves in the study area, we use the state-of-the-art $3^{\text {rd }}$-generation spectral Wave Model (WAM, Komen et al., 1994) modified for shallow water (Monbaliu et al., 2000). To allow investigation of the influence of externally generated waves generated propagating into the study area, a one-way nested model approach has been set up as follows. A $1^{\circ}$ North Atlantic model forces the boundary of a $1.85 \mathrm{~km}$ Irish Sea model (Fig. 1), so that any influence that swell might have in the study area will be included. To capture the external surge effects generated outside of the Irish Sea a one-way nested approach (Fig. 1b) from a 1/9 ${ }^{\circ}$ by $1 / 6^{\circ}$ Atlantic margin model to the $1.8 \mathrm{~km}$ Irish Sea model, using POLCOMS (Holt and 
James, 2001) has been applied. POLCOMS is a 3-dimensional hydrodynamic model, which can simulate both the barotropic and baroclinic processes, which arise from the tides, meteorological and riverine forcing (although density effects have not been included here). A 3-dimensional model is required to represent the vertical structure of the wind-induced currents (Jones and Davies, 1998). For the Irish Sea model wave-tide-surge interaction has been taken into account by 2-way coupling of POLCOMS and WAM (Osuna and Wolf, 2005). The coupling is achieved through the surface and bottom stress and wave refraction due to the presence of time varying current and elevation fields (Wolf et al., 2002).

For the November 1977 event the coarse grid models were driven by six-hourly, $\sim 1^{\circ}$ resolution ECMWF (ERA-40) wind and pressure data. For the fine resolution Irish Sea model higher resolution (both spatially, $1 / 2^{\circ}$ by $1 / 3^{\circ}$, and temporally, 3 hourly) wind and pressure data (Jones and Davies, 1998) were used to drive the model to simulate the wave and surge conditions. For the January 2007 event hourly wind and pressure data (referred to as mesoscale data) were provided by the UK Met Office North East Atlantic model, with a resolution of $1 / 9^{\circ}$ by $1 / 6^{\circ}(\sim 12 \mathrm{~km})$. The tides were included at the open boundary using the 15 constituents available in POLCOMS (Q1, $\mathrm{O} 1, \mathrm{P} 1, \mathrm{~S} 1, \mathrm{~K} 1,2 \mathrm{~N} 2, \mathrm{MU} 2, \mathrm{~N} 2, \mathrm{NU} 2, \mathrm{M} 2, \mathrm{~L} 2, \mathrm{~T} 2$, S2, K2 and M4). We then define the predicted surge elevation as the residual water level i.e. difference between the total elevation and the tidal elevation (from the model).

In the POLCOMS-WAM model the minimum water depth was set to $5 \mathrm{~m}$ with improved bathymetric data (NOOS data set: Zijderveld and Verlaan, 2004) in the eastern Irish Sea. This allowed resolution of the coastal bathymetric features, but prevented numerical instability with drying areas occurring in the model domain due to the tidal variations. Initial simulations with the standard $10 \mathrm{~m}$ minimum depth demonstrated the importance of including shallow areas, since a $10-30 \%$ increase in the peak surge elevation resulted at the shallow locations with this reduced minimum depth. Further work is planned using a 'wetting and drying' scheme, which will eliminate the need to fix a minimum depth.

\subsection{Representing the wind-stress}

We use POLCOMS with 6 vertical levels as a tide-surge model and as the hydrodynamic module of a coupled wave-current model. Depth-varying currents are calculated in the baroclinic mode (with constant density). The barotropic component solves the depth-averaged shallow water equations:

$$
\begin{aligned}
& \frac{\partial \zeta}{\partial t}+\frac{\partial}{\partial x}(h+\zeta) u+\frac{\partial}{\partial y}(h+\zeta) v=0 \\
& \frac{\partial u}{\partial t}+u \frac{\partial u}{\partial x}+v \frac{\partial u}{\partial y}+g \frac{\partial \zeta}{\partial x}=f v-\frac{1}{\rho_{w}} \frac{\partial p_{a}}{\partial x}-k \frac{u \sqrt{u^{2}+v^{2}}}{\rho_{w}(h+\zeta)}+\frac{\tau_{x}}{\rho_{w}(h+\zeta)} \\
& \frac{\partial v}{\partial t}+u \frac{\partial v}{\partial x}+v \frac{\partial v}{\partial y}+g \frac{\partial \zeta}{\partial y}=-f u-\frac{1}{\rho_{w}} \frac{\partial p_{a}}{\partial y}-k \frac{v \sqrt{u^{2}+v^{2}}}{\rho_{w}(h+\zeta)}+\frac{\tau_{y}}{\rho_{w}(h+\zeta)}
\end{aligned}
$$

where $t=$ time, $u, v=$ the depth-mean velocity components in $x$ - and $y$-direction respectively, $\zeta=$ surface elevation, $h=$ water depth, $g=$ gravitational acceleration, $f=$ Coriolis parameter, $k=$ quadratic bottom friction coefficient, $\tau_{x, y}=$ wind-stress in $x$ - 
and $y$-direction respectively, $\rho_{w}=$ water density and $p_{a}=$ atmospheric pressure at sea level.

Since the 1950's it has generally been accepted that the wind profile in the atmospheric boundary layer can be represented by a logarithmic law which appears very robust (Charnock, 1955). With the development of high frequency recording devices such as the sonic anemometer it has been possible to directly measure the surface stress (Reynold' stress) by means of eddy correlation and/or dissipation methods from the turbulent velocity fluctuations e.g. Smith and Banke (1975) and Taylor and Yelland (2001). These have led to various parameterisations of the stress in terms of the more readily available wind-speed at $10 \mathrm{~m}$ above the sea surface, $U_{10}$, giving the much-used empirical bulk formula such as $\mathrm{S} \& \mathrm{~B}$, and $\mathrm{Wu}$ (1982), among others.

Wind stress, $\tau$, depends on the air density, $\rho_{a}$, and friction velocity, $u_{*}$, which is related to the wind speed at $10 \mathrm{~m}, U_{10}$, by $u_{*}{ }^{2}=C_{D} U_{10}{ }^{2}$, where $C_{D}=$ a drag coefficient (Janssen, 2004):

$\tau=\rho_{a} u_{*}^{2}=\rho_{a} C_{D} u_{10}^{2}$

The S\&B formula:

$C_{D}=\left(0.63+0.066\left|U_{10}\right|\right) \times 10^{-3}$

was developed for winds up to $21 \mathrm{~m} / \mathrm{s}$ unlike the Charnock relation that holds for light $(<15 \mathrm{~m} / \mathrm{s}$ ) and high (up to $60 \mathrm{~m} / \mathrm{s}$ ) wind conditions and therefore a range of sea states (Wu, 1982). To correctly model the wind-stress in Eqs. (2) and (3) we need to select an appropriate roughness length $\mathrm{z}_{0}$. Charnock (1955) parameterised the roughness length, $z_{0}$, on dimensional grounds. By assuming momentum transfer from air to ocean is mainly through short surface gravity waves, then the roughness length is scaled by the acceleration of gravity, $g$, and $u_{*}$ :

$z_{0}=\frac{\alpha u_{*}^{2}}{g}$

The Charnock parameter, $\alpha$, is thought to be related to wave-age (Janssen, 2004), although this has been disputed (Taylor and Yelland, 2001), but it is often treated as constant in models with values between 0.0112 and $0.035(\mathrm{Wu}, 1980)$. Although $\alpha=$ 0.0185 seems to provide accurate representation of the surface stress for all sea states (Wu, 1982), a larger value is imposed for young (steep) wind-seas due to increased wave-wind coupling (Janssen, 1991) in WAM. In the wave model $\alpha$ is 'wave-age' dependent, thus varies in time and space. A higher value (0.0275) has also been found to be appropriate for surge modelling (Williams and Flather, 2000). This research aims to find the optimum constant and wave-dependent value for the eastern Irish Sea.

In the wave model applied here (WAM) Janssen's (1991) method is used to predict the effective roughness length, $z_{\mathrm{e}}$, of the sea surface as follows. He assumes that the wind profile has logarithmic shape for all sea states:

$U(z)=\frac{u_{*}}{\kappa} \ln \left(\frac{z+z_{1}}{z_{0}+z_{1}}\right)$

where $\kappa=$ von Karman's constant. The profile depends on a background roughness (capillary waves), $z_{0}$, which accounts for processes such as flow separation that are 
not considered explicitly. This roughness length is parameterised by a Charnock relation:

$z_{0}=\frac{\hat{\alpha} u_{*}^{2}}{g}$, where $\hat{\alpha}=$ constant

(8)

This is combined with the roughness length due to (short) gravity waves, $z_{1}$, to give the effective roughness, $z_{\mathrm{e}}=z_{0}+z_{1}$. The effective roughness is calculated in the wave model by a Charnock-like relation:

$z_{e}=\frac{\alpha u_{*}^{2}}{g}$, where $\alpha=\hat{\alpha} / \sqrt{1-\tau_{w} / \tau}$

where $\tau_{w}=$ the wave stress and $\tau=$ the total wind stress given by Eq. (5). The

constant $\hat{\alpha}$ was selected by trial and error as 0.01 , so for old wind-seas $\alpha=0.0185$ in Eq. (9), in agreement with observations collected by Wu (1982). Wave-age $\left(c_{p} / u_{*}\right)$ is used to measure the stage of development of the wind sea. A wave spectrum with relatively high peak frequency is termed 'young' $\left(c_{p} / u_{*} \sim 10\right)$ and refers to a sea state where the waves have just been generated by the wind. A saturated sea state is termed 'old' $\left(c_{p} / u_{*} \sim 30\right)$ and the wave energy hardly changes in time (Janssen, 1989). For old wind-seas $z_{\mathrm{e}} \approx z_{0}$ (the effective roughness is equivalent to that obtained without wave effects) and the stress behaves according to constant Charnock if $\tau_{w} / \tau$ is small, but as $\tau_{w} / \tau$ tends to one the stress is enhanced i.e. accounting for steep waves present in young wind-seas (Mastenbroek et al., 1993).

The surface drag coefficient in the standard POLCOMS model was taken from S\&B. For compatibility with the wave model a Charnock relation has now been implemented. In the latter case the surface roughness length, $z_{0}$, may be derived if the Charnock parameter is specified, or provided by the wave model through $u_{*}$, thus using the same wind-stress in the surge module as in the wave module. We wish to use a consistent drag law for both models, so that the effective roughness still gives the correct answer for 'old' wind-sea, in agreement with bulk formula (i.e. the no wave case using S\&B or Charnock), but is modified for 'young' wind-sea. Here, we impose $C_{D}$ using $u_{*}$ from the wave model, but an iterative method could be used to obtain $C_{D}$ from $\mathrm{z}_{\mathrm{e}}$. Subtle differences may occur due to the different numerics.

\subsection{The hindcast surge events}

Two significant surge events in Liverpool Bay have been simulated using the Irish Sea model. The eastern Irish Sea provides a simple test case in terms of geometry and negligible swell influence. The first is the November 1977 surge and the second the January 2007 surge. The model domain with locations of tide gauges and wave buoys during the events is shown in Fig. 2. Only coastal tide gauge data are available presently for validation of the surge. In the future pressure gauges located at the Liverpool Bay Coastal Observatory ${ }^{*}$ stations may also be used to validate the offshore surge.

The period $7^{\text {th }}-17^{\text {th }}$ November 1977 is a well-studied event due to the occurrence of two significantly different surge events (Jones and Davies, 1998). The first surge occurred on the $11^{\text {th }}-12^{\text {th }}$ November and was the result of an atmospheric depression

\footnotetext{
${ }^{*}$ Coastal Observatory web link: http://cobs.pol.ac.uk/
} 
crossing the region from west to east to the north of Scotland before moving on to northern Norway. The second surge occurred over a longer period during the $13^{\text {th }}$ $-15^{\text {th }}$ November and was in response to a less common, more southerly-tracking depression that moved from the west coast of Scotland to Denmark. In the first case $16 \mathrm{~m} / \mathrm{s}$ south-westerly winds in the eastern Irish Sea increased to $22 \mathrm{~m} / \mathrm{s}$ and veered round to the west (Fig. 3a). In the second instance, $15 \mathrm{~m} / \mathrm{s}$ north-westerly winds, increasing to $22-25 \mathrm{~m} / \mathrm{s}$, off the west coast of Scotland, forced water through the Northern Channel into the eastern Irish Sea, where the winds varied between 16-19m/s (Fig. 3b) (Jones and Davies, 1998). Surge elevation data obtained at five coastal tide gauges (Fig. 2) in the eastern Irish Sea during these events have been used to validate the model.

Jones and Davies (1998) show the local surge in the eastern Irish Sea is dominated by the external surge through the North Channel and from the Celtic Sea. The internally generated surge, due to the winds in the eastern Irish Sea, has a lower $(<0.5 \mathrm{~m})$ contribution to the total surge. During this event the tide was approaching the peak of maximum spring tide. The correspondingly large variation in water depth had a significant impact on the surge.

The surge on the $18^{\text {th }}$ January 2007 occurred due a depression travelling east to the north of Ireland and across Scotland. This caused $12 \mathrm{~m} / \mathrm{s}$ south westerly winds in the Irish Sea that increased in intensity to $18 \mathrm{~m} / \mathrm{s}$ and veered to the west reaching velocities of $22 \mathrm{~m} / \mathrm{s}$ before dying away (Fig. 4). The tide was mid-way into the spring tidal phase so although the tidal range was large the variation in water depth was not as extreme as in the 1977 surge event, so the tidal influence on the surge was reduced. Data to validate the surge were available at seven ports in the eastern Irish Sea and a wave buoy ${ }^{\dagger}$ provided wave height, $H_{s}$, and period, $T_{p}$, in Liverpool Bay. The locations are shown in Fig. 2. During this surge event the waves reached a peak height of $4.95 \mathrm{~m}$ with a peak period of $11.43 \mathrm{~s}$ at the wave buoy location.

\subsection{External Surge Calibration}

Due to lack of high resolution large scale wind data for the 1977 event POLCOMS was used to predict the tide-surge boundary conditions for the Irish Sea model using the ECMWF $1^{\circ}$ wind data. We found that POLCOMS under-predicted the external surge as a result of under-estimation of wind-speed due to low grid resolution and the use of S\&B with $U_{10}$ (the reasoning behind S\&B under-predicting the surge will be discussed more fully later). The predicted POLCOMS boundary conditions were therefore adjusted using tide gauge data at Ilfracombe and Malin, two coastal tide gauges close to the Irish Sea model boundary, using linear regression. This tuning was applied to the total water elevation at the boundary. Adding the tidal prediction of POLCOMS to the surge data at the two coastal tide gauges to obtain the total elevation meant that this method was indirectly tuning the predicted surge around the boundary. A different regression was found for the north and south boundary as shown in Fig. 5. The regression formulae were applied to the full length of both boundaries, with scaling along the boundary consistent with the model forcing. Surge elevation at Castletownsend confirmed that the regression formula applied at Ilfracombe would be sufficient to tune the full extent of the southern boundary. A

\footnotetext{
${ }^{\dagger}$ WaveNet web link: http://map.cefasdirect.co.uk/wavenet.asp
} 
continuity correction was then applied to the current velocities to preserve the water flux $\left(\boldsymbol{u}_{1}\left(h_{1}+\zeta\right)=\boldsymbol{u}_{2}\left(h_{2}+\zeta\right)\right)$ driving the velocity components at the boundaries.

During the second (lower) surge on the $15^{\text {th }}$ November, linked with winds veering to the northwest, the external surge through the North Channel appeared to be underpredicted. Fig. 5 shows the tuned results are biased to lower levels during the second event. For this reason we have only investigated the initial surge event defined as the 48 hour period from midday on the $10^{\text {th }}$ November until midday on the $12^{\text {th }}$

November. For the 2007 event the Operational Surge model at POL (CS3X) was used to provide the external boundary forcing, since it is tuned for accurate surge prediction using a Charnock relation (Williams and Flather, 2000). Tide gauge data at Port Rush and Ilfracombe confirmed that the boundary forcing (external surge) was adequately modelled using the CS3X.

\subsection{Model Accuracy}

With regard to coastal flooding, it is the peak in the total water level which is of most interest and requires accurate prediction. Due to model limitations the modelled tide will always contain errors due to the number of constituents included within the simulation and the grid resolution. The operational model thus uses harmonic tidal predictions at each coastal station added to the surge residual to give more accurate total water levels. In this case we are interested in the predicted surge (due to meteorological forcing) rather than the total water level. Fig. 6 shows the times of high water in relation to the (residual) surge elevation during the November 1977 surge event. The tidal modulation in the surge elevation shows how strong the tidesurge interaction is in the eastern Irish Sea. Generally, the peaks in surge avoid high water (Wolf, 1981; Horsburgh and Wilson, 2007). Interestingly the maximum surge occurs on the rising tide everywhere, except at Liverpool for the 1977 event only. A timing error in the tide gauge data during this initial event is therefore suspected.

The surge (actual or modelled) is defined here as the residual water level, i.e. the total (measured or modelled) water level minus the (predicted or modelled) tidal elevation. Since the (residual) surge is less extreme during high water (Fig. 6) the 'skew surge' becomes more important in flood risk management, since it gives an idea of how accurately the absolute water level above tidal high water is forecast (de Vries et al., 1995). Skew surge is the difference between the peaks in total water level and the nearest astronomical high tide level. Tide-surge interaction modifies the time of tidal high water, thus the absolute water level relative to predicted high water and not the residual water level is of more interest. The difference between the modelled and measured skew surge provides a measure of how accurately the peak total water elevation through time was predicted. We aim to accurately model the hindcast winddriven surge events discussed in section 2.3. Here we therefore concentrate on the (residual) surge, since this represents surge at all states of the tide.

To quantify the model performance we use three output metrics designed to assess the model accuracy through time. We also look at the RMS error of both the residual and skew surge and the bias in the peaks in (residual) surge. Although the RMS error provides an estimate of the model accuracy (averaged through time) it does not represent how significant this error is compared to the data. We have therefore developed an RMS percentage error function. This provides a measure of the 'goodness of fit' between the model and the data. The effect of a large error is 
enhanced through the squaring of the error, rewarding a good prediction and punishing a poor prediction. The size of the error is then compared to the variation in the data; again the effect of a large range is enhanced by squaring the range. In the following functions $D=$ the data, $M=$ the corresponding model prediction and the overbar indicates the mean value of the data set. The first function (trend error function, TEF), which is similar to a cost function (Holt et al., 2005), is defined as:

$$
T E F=\frac{100 \times R M S \text { error }}{\frac{1}{N} \sqrt{\sum_{n=1}^{N}\left(D_{n}-\bar{D}\right)^{2}}}=100 \sqrt{\frac{\sum_{n=1}^{N}\left(D_{n}-M_{n}\right)^{2}}{\sum_{n=1}^{N}\left(D_{n}-\bar{D}\right)^{2}}}
$$

This has been applied to the residual surge prediction. This metric provides an overall goodness of fit but does not discriminate the finer details. In shallow areas with large tidal range (as in Liverpool Bay) the surge level is strongly controlled by water depth. We therefore use two quantities to assess the absolute error in (i) the peak residual surge, which typically occurs near low water and (ii) the skew surge, which occurs close to high water when the surge set-up is close to minimum due to inverse water depth effects. To assess these two quantities we use a second function (peak error function, $P E F$ ), which is similar to a percentage model bias function (Allen et al., 2007), defined as:

$$
P E F=100 \frac{\frac{1}{N} \sum_{n=1}^{N}\left|\hat{D}_{n}-\hat{M}_{n}\right|}{\overline{\hat{D}}},
$$

where the circumflex indicates that only values at the peaks in either the residual (PEF-residual) surge or total water level (skew surge values, $P E F$-skew) are considered. The absolute value is taken to prevent averaging reducing the overall error. The size of the error is then compared to the size of the peak values to normalise the error. This function has been applied to the peaks in the residual surge to see how well the maximum surge (during low water level) is modelled, and also to the skew surge to see how well the surge is modelled at high water, when flood risk is greatest. The absolute error in the peak (residual) surge is considered the best measure of the effect of the wind-stress through time, thus we use the PEF-residual to determine which model set up is most accurate at surge prediction. This quantity is a measure of the model performance at low water and ignores any errors due to phase differences, which is considered unimportant operationally (de Vries et al., 1995).

We have spatially averaged (across five tide gauge locations in the area of interest) the magnitude of the accuracy measures over a 48-hour period $\left(12: 0010^{\text {th }}-12: 00\right.$ $12^{\text {th }}$ November) in 1977 and a 24-hour period (00:00 $18^{\text {th }}-00: 0019^{\text {th }}$ January) in 2007. These average quantities allow assessment of how well the model predicts (i) the peaks in a surge event (close to low water), (ii) the peaks in total water level (close to high water) and (iii) the surge level over one or two tidal cycles, across a region of varying topography. These measures access more than one time instant hence the effects of variations in the wave field and depth are accounted for.

We now aim to tune POLCOMS to obtain the optimum (residual) surge prediction that is valid for different surge events and different locations around the eastern Irish Sea, obtaining a globally valid model set up for any wind condition. 


\section{Results}

POLCOMS-WAM was used to hindcast the November 1977 storm surge event. The model was tuned to obtain the most accurate (regional) surge prediction across five coastal tide gauges in the eastern Irish Sea. To validate the new model set up the January 2007 event was then simulated using a subset of the initial model configurations.

\subsection{Wave model results}

The wave model accurately modelled $H_{s}$ and $T_{m 02}$ during the 2007 surge event (Fig. 7), with an RMS error of $0.63 \mathrm{~m}$ and $0.73 \mathrm{~s}$ respectively, an $\mathrm{R}^{2}$ value of 0.83 and 0.70 respectively, a bias in the wave height of $0.08 \mathrm{~m}$ and a bias in $T_{m 02}$ wave period of $-0.24 \mathrm{~s}$. Compared to the 2007 event the waves during the 1977 event were lower (Fig. 8). By including external wave boundary forcing in 1977 (Fig. 9) we have also demonstrated that external swell propagating into the Irish Sea has an insignificant influence in the eastern Irish Sea. This is due to the sheltering effects of the coastline within the eastern Irish Sea and Liverpool Bay in particular. Centrally and in the south of the Irish Sea external waves propagating through St George's Channel are important. The narrow width of the North Channel prevents significant external wave propagation into the northern Irish Sea.

\subsubsection{WAM model fix}

The conditions in the eastern Irish Sea prevent 'old waves' occurring at the time of peak surge (Fig. 10). Janssen (1989) demonstrates that for very young wave conditions $\left(c_{p} / u_{*}<15\right)$ in the absence of swell $\tau_{w} / \tau>1$, where $\tau_{w}$ is the wave related stress and $\tau$ is defined by Eq. (4). Since this is physically unrealistic an upper limit $\left(\tau_{w} / \tau \leq 0.999\right)$ is imposed to prevent numerical instability in the computation of $\alpha$ in WAM. This model application tests the robustness of the wave-dependent Charnock parameter and computation procedure in WAM when applied to enclosed seas.

In the eastern Irish Sea wind conditions exceeding $\sim 18 \mathrm{~m} / \mathrm{s}$ combined with no swell influence should force the Charnock-like parameter to reaches its upper limit $\alpha=0.31$ (equivalent to $\tau_{w} / \tau \leq 0.999$ ) Figs. 11 and 12. The computation method updates $\alpha, u_{*}$ and $z_{e}$ using $\tau_{w}$ from the previous time step before re-calculating $\tau_{w}$. WAM uses $\tau_{w, t-1}$ to predict $\tau_{t}$ and forces $\tau_{w, t-1} / \tau_{t}<0.99999$, where subscript $t=$ time, thus at the stage when $\alpha, u_{*}$ and $z_{e}$ are calculated $\tau_{w, t-1} / \tau_{t}$ is less than unity and no limit is applied allowing realistic values to be computed for application in the surge model. The resulting $\alpha$ value is shown in the bottom panels of Figs. 11 and 12 compared with the constant $\alpha$ value (0.0185) proposed by Wu (1982) to be accurate for all wind conditions (sea states).

At times of peak surge, wave-age dependence is maintained in the surface roughness across the Irish Sea and not imposed as a constant limiting value. This is due to the sequence of computations in WAM. Predicting the total surface stress before updating the total wave stress prevents $\alpha$ taking its upper limit (Fig. 13), therefore wave-age does influence the surge prediction and realistic $u_{*}$ and $z_{e}$ values are computed, although the updated $\tau_{w}$ exceeds $\tau$ (Fig. 14). In the global WAM model a range of $\alpha=0.01-0.05$ is found for $U_{10}=1-25 \mathrm{~m} / \mathrm{s}$ (Bidlot and Janssen, 2003) and wave-ages $\left(c_{p} / u_{*}\right)>15$ (Janssen, 2004). Due to the asymptotic nature of $\alpha$ its value rapidly increases for young-waves. We show that during surge conditions the very 
young waves in the eastern Irish Sea lead to larger $\alpha$ values (up to 0.07) (Fig. 13). As long as $z_{e}$ (in place of $z_{0}$ ) or $u_{*}$ is transferred to the surge model then accurate results are achieved, but if $\tau_{w} / \tau$ is transferred unrealistically large Charnock parameters, and thus surge elevations, will result. The following figures are for the time of the peak surge. Fig. 13 shows that with increasing fetch the waves become older, except within Liverpool Bay where the waves decrease in age due to shoaling (Taylor and Yelland, 2001). There is a steep gradient in $\alpha$ along the east coast of Ireland, due to the sheltering effect of land on the wind. The variation in $\alpha$ across the Irish Sea associated with wave-age $\left(\tau_{\mathrm{w}} / \tau\right)$, may not be accurate for short fetches and young seas, for example along the east coast of Ireland (Taylor and Yelland, 2001). The relatively steep waves have low wave height, the two effects thus cancelling each other out to create a roughness similar (or slightly less) than for longer fetches. This effect is not seen here, since wave height is not accounted for. However, in shoaling conditions as in Liverpool Bay, the roughness will be significantly increased (Taylor and Yelland, 2001).

When computing $z_{1}$ (defined in Eq. (7)) using Eq. (6) to obtain the high-frequency contribution to the wave stress, the standard code within WAM sets an upper limit for $\alpha_{1}=0.1$, where $\alpha_{1}=\alpha-\hat{\alpha}$, and $\hat{\alpha}=0.01$. Under limiting conditions this leads to inconsistent $\alpha$ and $u_{*}$ values used to calculate $z_{e}$. Bidlot and Janssen (2003) improved the numerical evaluation of the high-frequency contribution to the wave stress and total stress by doubling the resolution of total stress look-up table, along with increasing the upper limit of $\alpha_{1}$ to 0.2 . Here, we have imposed the table resolution of Bidlot and Janssen (2003) and also imposed an upper limit of $\alpha_{1}=0.3$ to obtain consistent $z_{e}$ and $u_{*}$ values.

\subsection{November 1977 event}

The surge in Liverpool Bay during November 1977 was predicted using different representations of the surface stress in POLCOMS. The model was initially run using stand-alone POLCOMS. The surface stress was predicted using S\&B with $U_{10}$ and $1.1 U_{10}\left(\sim U_{25}\right)$ as shown in Fig. 15. A $10 \%$ enhancement of the winds is thought to be acceptable since the biggest uncertainty is in wind prediction. It was found that for the deeper coastal tide gauges (Douglas and Workington) that the enhanced wind velocity improved the peak surge prediction. For the shallower coastal tide gauges (Heysham, Hilbre and Liverpool) the standard wind speed performed better.

These two stress relationships can be well approximated by using the Charnock method with (different) constant values (Fig. 15). The first, $\alpha=0.0275$, is the same as that used in the CS3 model and corresponds to $S \& B U_{25}$. The second, $\alpha=0.0144$ is the same as that used by Janssen (1988) and represents S\&B $U_{10}$. Implementing the Charnock procedure in POLCOMS allows the model to be coupled to WAM, while having the option to keep the surface stress computation decoupled. Use of a Charnock-type surface stress parameterisation in both of the models allows more consistency in the surface stress computation. Other wave-current interactions are also included (e.g. the enhancement of bottom friction due to waves). Fig. 15 and Table 1 illustrate that the influence of waves on the surge prediction is negligible when the surface stress is decoupled. This is contradictory to the results of Jones and Davies (1998). Thus, it is more computationally efficient, and of similar accuracy, to 
run a hydrodynamic model with a tuned Charnock parameter for a specific location rather than running a coupled wave-current model.

At all five locations S\&B with $U_{10}$ is better at predicting the initial stages (peaks) of the surge. As the winds increase through time $S \& B$ with $U_{10}$ remains more accurate at the shallower coastal tide gauges, while $\mathrm{S} \& \mathrm{~B}$ with $1.1 U_{10}$ becomes more accurate at the deeper coastal tide gauges. By using a wave-dependent Charnock parameter, i.e. using the stress predicted by WAM in POLCOMS, we aim to capture both the temporal and spatial changes in the surface roughness due to the development of the wave field. Mastenbroek et al. (1993) found implementing an untuned wavedependent drag coefficient led to over-prediction of the peak surges, but here the finer model resolution (an order of magnitude finer spatially) gave realistic surge prediction (black solid line in Fig.16). In this investigation the peak (residual) surge prediction is most important as it represents the effect of the wind-stress on the surge, we therefore want the best PEF-residual and peak bias (Table 1, Fig. 16). We also require a good surge prediction at all states of the tide, hence a good regional TEF (Table 1, Fig. 16).

We found that a better regional TEF, PEF-skew and peak bias was achieved using $\alpha=$ 0.0275 (with and without waves) or S\&B with $U_{25}$, than using $\alpha=0.0144$ (with and without waves) or S\&B with $U_{10}$. But the opposite was true for the PEF-residual. This demonstrates that the choice of (constant) $\alpha$ applied in a surge model, will depend upon which aspect of the surge is most important to the model application. Using a wave-dependent Charnock parameter (WD) gave the best regional PEFresidual and bias in the main peak, and an intermediate regional TEF and $P E F$-skew compared to the constant $\alpha$ values (Table 1). Using a wave-dependent $\alpha$ therefore provides the most accurate prediction of the surge peaks across the region, although $\alpha$ $=0.0275$ (with and without waves) provides the best regional skew surge prediction and general surge trend over time.

Fig. 16 shows that the wave-dependent (residual) surge prediction is of similar value to that of $\alpha=0.0275$ ( $\mathrm{S} \& \mathrm{~B}$ with $1.1 U_{10}$ ) as the surge elevation increases. After the surge peak the wave-dependent (residual) surge prediction then tends towards $\alpha=$ 0.0144 (S\&B with $U_{10}$ ). This shift in bias between the constant $\alpha$ values is location dependent, giving the best regional peak surge prediction. The time variation of the wave-dependent $\alpha$ value produced more accurate peaks in the surge than using constant $\alpha$ over the region (Table 1).

Running the fully coupled wave-current model with and without external wave boundary conditions (to the Irish Sea) (Fig. 16) demonstrated that the influence of the more developed waves does have a small impact on the surge prediction (in the more exposed places). The only changes occur during the peaks in surge. Initially (for the first two surge peaks) the effect of the external waves is to increase the surge elevation and then for the final peak to decrease the surge elevation. This is due to the external waves becoming more fully-developed (swell) with time leading to reduced surface roughness. The inclusion of external waves causes the regional measures of accuracy to become worse (Table 1). The larger regional bias is due to an increased negative bias at Liverpool and Workington being averaged with a reduced positive bias at Douglas, Hilbre and Heysham. Locally, the inclusion of external wave conditions improves the peak bias at many of the locations (Fig. 16). External waves 
propagating into the Irish Sea from the Atlantic through the North Channel and the Celtic Sea have negligible impact on the surge prediction in the eastern Irish Sea. Hence, it is more computationally efficient to only nest the hydrodynamic model for this area. This is due to the shallow $(<40 \mathrm{~m})$ depths in the Irish Sea and the sheltering effects from Anglesey and the narrow North Channel preventing external swell propagating into the study area. Within the eastern Irish Sea locally generated wind waves are of most importance and due to the limited fetch these are often young waves that produce increased surface stresses. These results imply that the short fetch in the eastern Irish Sea is enough for wave-age to influence the surge prediction.

\subsubsection{The 1977 tidal simulation}

The POLCOMS tidal prediction for the 1977 surge event was compared to the astronomical tide at the five coastal tide gauges investigated. We found that POLCOMS consistently over-predicted high water by $1-7 \%$ and under-predicted low water by $5-12 \%$. This over-predicted tidal range is why the larger $\alpha(0.0275)$ improved the TEF and skew surge results. The greater depth at high water reduced the wind influence on the surge, while this $\alpha$ enhanced the stress. Thus the surge at higher water elevations (the troughs in the residual surge), and hence the skew surge, were more accurately predicted. The peak residual surge, however, was not. The lower water depth increased the wind influence, which when combined with an increased stress due a large $\alpha$ caused an over-prediction of the peak residual surge. Since the peak values in residual surge have minimal effect on the RMS error, $\alpha=$ 0.0275 therefore improves the TEF accuracy. The large tidal range during the 1977 event means that tuning the Charnock parameter to improve the peak (residual) surge caused the skew surge prediction to become worse and visa versa. Thus a better tidal prediction would be desirable to more accurately tune the constant $\alpha$.

\subsection{Validation using January 2007}

The January 2007 surge event was simulated using a subset of the Charnock methods applied to the November 1977 event. These runs, with better winds, verify that the methods used are the most appropriate for accurate surge prediction, and also allow assessment of the wave modelling during this more recent storm event, since wave data have been recorded since 2002. The results have been obtained for the seven available coastal tide gauges in the eastern Irish Sea, but only analysed at five coastal tide gauges around the eastern Irish Sea consistent with those used in the 1977 event.

\subsubsection{Effect of model resolution}

Across the region a comparison of the (residual) surge prediction made by the operational surge model (CS3X) and POLCOMS, with the same set up as the operational surge model (no waves, $\alpha=0.0275$ and tide-surge boundary conditions from CS3X), has been made. Fig. 17 demonstrates that the POLCOMS model with higher spatial resolution can better capture the trends in the surge within the eastern Irish Sea. Both models have the lowest accuracy at Llandudno and Holyhead. This may be due to local wind and sheltering effects. Since POLCOMS does not resolve Holyhead harbour and Llandudno is a secondary port we omit these tide gauges and concentrate on the five coastal tide gauges in the eastern Irish Sea to validate the model. At the Irish Sea model boundary, we found that the operational surge model under-predicted the mean surge level by $8 \%$ at the southern boundary (Ilfracombe) and over-predicted it by $23 \%$ in through the North Channel (Port Rush). This overprediction may also be the reason for the over-predicted surge conditions at 
Llandudno and Holyhead. With distance from the North Channel the POLCOMS predictions improve, demonstrating that even when a surge propagates from the south west the surge through the North Channel may have significant impact in the eastern Irish Sea.

\subsubsection{Surge results}

The tuned model settings for the 1977 event were applied to the 2007 event. The regionally averaged measures of model accuracy are given in Table 2 . Table 2 gives the five tide gauge average values, for Hilbre, Heysham, Liverpool, Port Erin and Workington. This provides a consistent region (Liverpool Bay area of the eastern Irish Sea) for comparison with the 1977 surge event and also reduces errors in the surge prediction resulting from the boundary conditions.

Again we found that wave effects on the bottom friction had a negligible impact on the simulations with constant $\alpha$. Also, the constant parameter settings $(0.0144$ and 0.0275 ) provided fairly accurate surge predictions (Fig. 18). For this event both constant Charnock parameters performed equally well at capturing the peak (residual) surge at Heysham, while $\alpha=0.0275$ was better at Hilbre compared with $\alpha=0.0144$ at these two locations in the 1977 event. At Workington and Port Erin $\alpha=0.0144$ was better for this surge event unlike the 1977 event when $\alpha=0.0275$ was better at Workington and Douglas. At Liverpool $\alpha=0.0275$ remained the better option. Compared to the 1977 event the best constant $\alpha$ for the TEF and the PEF-residual has reversed. This time including wave effects in the surface stress only improved the PEF-residual, while the other three metrics became worse. This model therefore still provides the best prediction of the peaks in the surge in Liverpool Bay (Liverpool and Hilbre) and is very similar to $\alpha=0.0275$ through time.

The phase and magnitude of the peak surge are accurately modelled at Heysham, Hilbre and Liverpool. At Port Erin and Workington the peak is overestimated and lags that measured at the tide gauges. This is most likely attributable to errors in the wind forcing. Comparison of the mesoscale wind data (used to drive the model) and data collected every 10minutes from the Hilbre met station illustrated that a slight (1.75hr) phase lag and increase in magnitude (by $7 \%$ ) occurred at this location. The phase error in the wind forcing may also explain why the modelled surge event persists for longer duration than suggested in the data at all tide gauge locations.

\subsubsection{Tidal simulation in 2007}

Again the tidal range is over-predicted by POLCOMS, but the range is not as large as during the 1977 event. Hence the influence of the inaccuracy in the tide is not as great and the effects of a large $\alpha(0.0275)$ makes the general surge prediction worse, except at high water. The tidal range also seems to affect the choice of constant Charnock parameter at a location, to capture the peak residual surge. The deeper low water levels during the 2007 event compared to the 1977 event means the lower Charnock parameter is now favoured in shallow locations. The tide-surge interaction is also less significant in 2007, especially at the deeper coastal tide gauges. The effect of the under-predicted low water depth therefore has less effect and the lower Charnock value now gives a better peak (residual) surge prediction. The smaller (compared to 1977) tidal range during the 2007 event reduced the tide-surge interaction, thus tuning the Charnock parameter to improve the peak (residual) surge also improved the skew surge prediction. 


\subsection{Wind-stress predictions}

The wind-stress predicted by POLCOMS is illustrated in Fig. 19 for the 1977 event and Fig. 20 for the 2007 event. During the 1977 surge there are three distinct peaks in the wind-stress. These peaks do not coincide with the times of peak surge, the $2^{\text {nd }}$ and $3^{\text {rd }}$ peak are also quite close to the times of high water. This implies that tide-surge interaction is considerable as a result of the large tidal range during the 1977 surge, thus causing significant tidal modulation in the residual surge, as already discussed.

In 2007 there was a single dominant peak in the wind stress which occurred close to high water, except at Liverpool and Hilbre. At these two locations the peak in the wind-stress occurs later (close to low water). Tide-surge interaction can explain the enhanced second peak and tidal modulation at these two locations. Heysham also has considerable tide-surge modulation, which can be explained by the more symmetrical shape in the wind-stress peak (Fig. 20). At the time of low water the stress still has a relatively significant impact. At Port Erin and Workington no tide-surge modulation is seen as a result of the asymmetric peak in the wind-stress. The stress gradually increases and rapidly decreases, so its influence at low tide is relatively less significant than at high tide, which also explains why the residual surge peak is lower. During this surge event the tidal range is less than that during the 1977 event, so any tidal modulation of the surge is much weaker than in November 1977. A further point of interest is the effect of waves on the timing of the peak stress at Hilbre.

We have found that during a surge event it depends on the location (effect of water depth) and the waves during the event as to whether the peak stress is enhanced by waves (WD) or remains comparable to using a constant (0.0144) Charnock parameter. At the wave buoy location the wave-age drops from 18 just before the surge to 4 at the peak of the surge in January 2007, before increasing to 12 as the winds drop. Across the eastern Irish Sea there is also noticeable variation in wave-age at the peak of a surge event. The shoaling waves in Liverpool Bay (Heysham, Hilbre and Liverpool area) are younger $\left(c_{p} / u_{*} \sim 5\right)$ than elsewhere in the eastern Irish Sea $\left(c_{p} / u_{*} \sim 10\right)$. The Isle of Man has a sheltering effect from the wind resulting in old waves along its leeward side $\left(c_{p} / u_{*} \sim 15\right)$. Older waves $\left(c_{p} / u_{*} \sim 11-13\right)$ due to the sheltering effects of the North Channel also occur to windward of the Isle of Man. We have shown that the Charnock relation already captures a significant amount of the sea state variation (as did $\mathrm{Wu}, 1982$ ) across the eastern Irish Sea, since accurate surge prediction is achieved at five different locations. But to improve the peaks in surge prediction wave-dependence may be included in the calculation of the Charnock parameter.

\section{Discussion}

The model was tested with different wind stress using the S\&B (uncoupled) and the Charnock (coupled and uncoupled) formulations. The model set up was calibrated using the November 1977 surge event and then validated using an extreme event in January 2007, for which good high resolution wind data, surge model boundary conditions, coastal tide gauge data and wave data are available.

In the 1977 event the model simulation at Liverpool is out of phase with the data. Since the surge between Hilbre and Liverpool is similar in 2007 it is suspected that 
timing errors in the Liverpool tide gauge occurred during the 1977 event. However, local wind effects could be important in one event but not the other. The main surge peak just after the $12^{\text {th }}$ November is greatly under-predicted. It is thought the errors in phase and magnitude are related to the wind resolution in 1977 missing local effects within the estuary, rather than model resolution, since the 2007 surge is much more accurately predicted. At Douglas and Hilbre there is a secondary peak in the surge on the $12^{\text {th }}$ November 1977, which is missed by the model. Due to the narrow time frame in which this peak occurs (1.95hours) and wind data being provided every 3 hours the model does not capture this brief event as a result of interpolation smoothing the wind field. This highlights the need for high resolution met data to prevent smoothing of the surge events and maintain the peaks in the signal. The loss of this spike may have influenced the under-prediction of the second peak at Liverpool Bay.

We have also demonstrated that it is important to accurately simulate the tidal range, since tide-surge interaction can be important within Liverpool Bay. In the November 1977 significant tidal modulation occurred in the surge, while in January 2007 the modulation was less important. This demonstrates that the tidal range is important in controlling the extent of the surge-tide interaction. At Douglas during the $10^{\text {th }}-11^{\text {th }}$ November 1977 the tidal variation in the tide gauge data is lost. It is thought that this may be due to errors in the methods used to process the data and that the model is accurate in simulating tidal modulation during this period.

Wetting and drying of inter-tidal zones has not been included within this model simulation, but would be advantageous. To prevent numerical instability during low tidal levels in shallow water a minimum depth must be set. This research highlighted the need for the minimum water depth to be as low as possible to accurately simulate surge events in shallow locations, in this case $5 \mathrm{~m}$ (however coastal tide gauges are generally in a minimum of $5 \mathrm{~m}$ water depth). This is due to the finite difference discretisation of the sea area in POLCOMS, as the surface elevation gradient is balanced by the wind-stress divided by depth and hence the effect of wind-stress is much stronger in shallower water. Therefore the bathymetry in shallow regions must be as accurate as possible. By comparing the surge prediction of POLCOMS to that of CS3X we also show grid resolution is important in surge prediction.

S\&B was initially developed for low $(<21 \mathrm{~m} / \mathrm{s})$ wind conditions, but relations with a similar form to S\&B have proven to work well for strong (up to $60 \mathrm{~m} / \mathrm{s}$ ) wind conditions, even though changes in sea state are not explicitly considered in this method (Wu, 1982). When using S\&B for the November 1977 surge we found it necessary to increase the $10 \mathrm{~m}$ wind velocity by a factor of 1.1 at deeper locations to get the correct surge (as found in Williams and Flather, 2000, for the UK operational surge model), although in shallower areas the original S\&B formulation worked well for this case. Again this is somewhat an artefact of the finite difference discretisation causing a bias in the wind-stress to be much more important in shallower water. For the January 2007 event the opposite occurred: a higher Charnock value and therefore $U_{25}$ worked better in shallow water. This may be related to the smaller tidal range during this event. The deeper low water levels reduce the depth integrated stress effect compared to the 1977 event and thus require an enhanced stress to capture the surge. For coarse grids such as CS3X and the Atlantic Margin POLCOMS model the average depth within a grid cell near the coast will be greater that that of the fine 
resolution Irish Sea POLCOMS model. This is why the wind requires scaling in the coarse models for S\&B to work well. The fact that POLCOMS used S\&B with low resolution $U_{10}$ data and no scaling, led to the under-prediction of the boundary conditions to force the external surge in November 1977. It was therefore necessary to modify the prediction by a linear regression to obtain water levels similar to those measured close to the boundary. Since the CS3X model, with a tuned Charnock parameter that used high resolution $U_{10}$ data, was available for the January 2007 surge an accurate external boundary forcing was provided without the need to adjust the boundary conditions.

Interestingly, it was found that with regard to predicting the peak (residual) surge $\alpha=$ 0.0144 ( $\equiv$ S\&B with $U_{10}$ ) was better in shallow water and $\alpha=0.0275$ ( $\equiv$ S\&B with $U_{25}$ ) was better in deeper water for the November 1977 surge and visa versa for the January 2007 surge. For the bias in skew surge the opposite was true in the 1977 case, but not for the 2007 case. This demonstrates how time variation in the tidal elevation is important and can affect the tuning of the Charnock parameter, depending on whether the user requires accurate surge prediction at lower water levels (peak residual surge) or higher water levels (skew surge). By using the wave-dependent Charnock parameter we have accurately simulated the surge at most states of the tide. In the eastern Irish Sea $\alpha$ took a maximum value of 0.07 (Fig. 13). These extreme values are a result of shoaling in Liverpool Bay and fetch-limited conditions along the east coast of Ireland, although the latter is questionable (Taylor and Yelland, 2001).

The PEF-residual has been chosen as the most important accuracy measure to tune the model set up, since this parameter measures the accuracy of the surge during low water levels when the wind-stress has most influence. A constant Charnock parameter can be tuned to obtain the best value for a given accuracy measure (Table 1 and 2), but the constant value which is most accurate for each measure varies from surge to surge. For example $\alpha=0.0275$ performs best for the PEF-residual in 2007, while $\alpha=0.0144$ is better in 1977. On average, for these two south-westerly/westerly surge events, $\alpha=0.0275$ is always the most accurate constant value for the metrics considered (Table 3 ) and most importantly gives the best PEF-residual. The wavedependent Charnock parameter improves the PEF-residual and gives a similar level of accuracy for the peak bias. Hence this model set up is more accurate than applying a single constant Charnock value to different surges over a long time period (Table 3 ). We have shown that the Charnock value should vary, depending on sea state, from values below 0.0144 to above 0.0275 during a surge event (Figs. 16 and 18 and Figs. 19 and 20). Wu (1982) demonstrated that an intermediate Charnock constant of 0.0185 accurately predicted surface stress for all sea states. Table 3 shows that $\alpha=$ 0.0185 provides an intermediate overall accuracy than using $\alpha=0.0144$ or $\alpha=0.0275$. It must be noted that the results presented here could be biased to shallow locations since three out of the five coastal tide gauges were considered shallow and also to south-westerly/westerly surge event. But since the constant Charnock value that performs best at a shallow location is often opposite to that which performs best at a deep location, we seek a Charnock value that will perform well across an entire domain. We have achieved an intermediate surge prediction compared to using the two constant Charnock parameters by using $\alpha=0.0185$. But the most accurate representation of the peaks in surge was obtained by using the wave-dependent Charnock-like parameter from the wave model, where $\alpha>0.01$ and typically $\alpha \geq$ 0.0185 . For different surge events we have shown contrary to the findings of 
Mastenbroek et al. (1993) that there is no single constant Charnock parameter that captures the behaviour of the wave-dependent parameter. Also, a lower (0.0275) value was found to give better surge prediction than that $(0.032)$ found by Mastenbroek et al. (1993). This could be related to the finer grid resolution applied in the Irish Sea.

We have shown that a surge can be accurately predicted across the Irish Sea by tuning a constant Charnock parameter, without the need for including waves. This allows quick efficient computations to be performed. In both shallow and deep water the effect of waves through bottom friction had negligible impact on the surge prediction. We have demonstrated that for a specific location in Liverpool Bay S\&B can give as good a prediction as Charnock with a constant parameter, when they are both scaled for that location and surge event. Although the eastern Irish Sea is dominated by young wind-seas during a surge event, there is variation in the wave-age across the region and during the surge event itself. In extreme storm conditions in the eastern Irish Sea the young waves cause a large surface roughness. This resulting surface stress is therefore greater than that predicted by S\&B which is only weakly dependent on sea state through $U_{10}$. For more accurate global surge prediction, using a wavedependent Charnock parameter removes the need for finding an optimum constant Charnock parameter, which will be dependent on the location, surge event and model grid resolution. The use of look-up tables and iterative methods could be implemented into a stand-alone model to include wave-age dependence, without the need for model coupling, to keep computation time down.

\section{Conclusions}

The eastern Irish Sea provides simple wave-surge conditions. A consistent method to calculate the surface stress in the wave and surge models has been implemented. We have shown that a constant Charnock parameter can be tuned to give good surge results, but not necessarily optimum over time and space. A relatively large Charnock value (e.g. compared to $\mathrm{Wu}, 1982$ ) was required. Using a wave-related surface stress gave variation in the Charnock parameter with a physical basis. However, controversy still exists over the 'wave-age' dependence of the surface drag coefficient.

The simulations of two extreme surge events in Liverpool Bay have shown that the external swell from the North Atlantic has negligible effect on the wave and surge prediction. In contrast the external surge from the North Atlantic dominates the local surge. We have found S\&B gives good predictions for high resolution models and shallow areas. When using a coarse model grid, or investigating surge events in deeper water, the wind velocity requires scaling (to represent $U_{25} \sim 1.1 U_{10}$ ). The S\&B method can be represented by a Charnock relation with a (tuned) constant parameter. This provides a consistent method to represent the surface stress in both the wave and hydrodynamic model which facilitates coupling of the models. Taking wave effects into account has little impact on surge prediction unless the surface stress term is also coupled within the model. Applying a wave-dependent Charnock-like parameter provides spatial and temporal variation in the surface stress relation. This allows peak surge conditions due to different surge events to be more accurately modelled across a region. 
We have tried to resolve the question of whether surge model accuracy is improved by including a wave-dependent surface stress. This should only occur if there are significant wave-age changes across a region, in which case a constant Charnock parameter will not suffice. The modelling results suggest that at the time of peak surge the waves are still considered very 'young' in the Irish Sea. Conditions in the eastern Irish Sea (with short fetch and shallow depths) prevent 'old' waves occurring. Although the Charnock relation was not developed for shallow, enclosed coastal basins it seems to hold for such conditions, as does the Charnock-like procedure in WAM. Wave-steepness and not wave-age relations have been found to perform better in shallow (and shoaling), fetch-limited conditions (Drennan, et al., 2005), but we find that using $\tau_{\mathrm{w}} / \tau$ to represent wave-age effects well predicts surges in Liverpool Bay. Due to the sequence of computation in WAM the wave-dependent $\alpha$ is prevented from achieving its unrealistic upper limit at peak surge. During a surge event the wave-dependent $\alpha$ increases from 0.0185 to a maximum of 0.07 in Liverpool Bay, a result of very young shoaling waves. During a surge event local waves therefore give a significant enhancement of the surface roughness. We have shown that surge events in this region are susceptible to turning winds (younger wind sea modifying the surface roughness at peak surge), although they require steady wind for a considerable time period to build the surge set up. Scaling of $z_{\mathrm{e}}$ was not required in the surge module to produce the appropriate stress for storm surges, the full waveage dependent stress from the wave module (Janssen, 1991) was retained. If the wave-dependence of the Charnock parameter is to be ignored then $\alpha=0.0275$ provides a good parameterisation (on average) of the wind-stress over long time periods in the eastern Irish Sea. Further investigation for the whole shelf is desirable to see how representative this method is.

\section{Acknowledgements}

This work was carried out as part of the NERC FREE CoFEE project, with the help and advice of Eric Jones regarding the 1977 surge event. His provision of wind data was gratefully received. Jane Williams is acknowledged for her assistance in providing model output and met. data for the 2007 surge event. Alejandro Souza is thanked for comments regarding the modelling results and presentation of data. Richard Pawlowicz is acknowledged for providing mapping tools to present the data. BODC and CEFAS (Wavenet) are thanked for providing data to validate the simulations.

\section{References}

Allen, J.I., Holt, J.T., Blackford, J., Proctor, R. (2007) Error quantification of a highresolution coupled hydrodynamic-ecosystem coastal-ocean model: Part 2. Chlorophyll-a nutrients and SPM. Journal of Marine Systems, 68(3-4): 381-404.

Bidlot, J.-R., Janssen, P. (2003) Unresolved bathymetry, neutral winds, and new stress tables in WAM. Internal Memorandum Research Department R60.9/JB/0400, ECMWF, Reading, U.K, 18pp.

Charnock, H. (1955) Wind-stress on a water surface. Quarterly Journal of the Royal Meteorological Society, 81(350), 639-640.

De Vries, H., Breton, M., De Mulder, T., Krestenitis, Y., Ozer, J., Proctor, R., Ruddick, K., Salomon, J.C., Voorrips, A. (1995) A comparison of 2D storm surge models applied to three shallow European seas. Environmental Software, 10(1): 23-42. 
Drennan, W.M., Taylor, P.K., Yelland, M.J. 2005. Parameterizing the Sea Surface Roughness. Journal of Physical Oceanography, 35(5): 835-848, DOI: 10.1175/JPO2704.1

Gill, A.E. (1982) Atmosphere-Ocean Dynamics. Academic Press, 662pp.

Holt, J.T., Allen, J.I., Proctor, R., Gilbert, F. (2005) Error quantification of a highresolution coupled hydrodynamic-ecosystem coastal-ocean model: Part 1 model overview and assessment of the hydrodynamics. Journal of Marine Systems, 57(1-2): 167-188.

Holt, J.T., James, D.J. (2001) An s coordinate density evolving model of the northwest European continental shelf: 1, Model description and density structure. Journal of Geophysical Research, 106(C7): 14,015-14,034.

Horsburgh, K.J., Wilson, C. (2007) Tide-surge interaction and its role in the distribution of surge residuals in the North Sea. Journal of Geophysical Research, 112(C08003): doi:10.1029/2006JC004033.

Janssen, P.A.E.M. (1989) Wave-induced stress and the drag of air flow over sea waves. Journal of Physical Oceanography, 19(6): 745-754.

Janssen, P.A.E.M. (1991) Quasi-linear theory of wind-wave generation applied to wave forecasting. Journal of Physical Oceanography, 21(11): 163-1642.

Janssen, P.A.E.M. (2004) The interaction of ocean waves and wind. Cambridge University Press, Cambridge, 300pp.

Janssen, P. A. E. M., Saetra, O., Wettre, C., Hersbach, H. (2004) Impact of the sea state on the atmosphere and ocean, Annales Hydrographiques, 3(772): 3.13.23 .

Jones, J.E., Davies, A.M. (1998) Storm surge computations for the Irish Sea using a three-dimensional numerical model including wave-current interaction Continental Shelf Research 18(2): 201-251.

Komen, G.J., Cavaleri, L., Donelan, M., Hasselmann, K., Hasselmann, S., Janssen, P.A.E.M. (1994) Dynamics and modelling of ocean waves Cambridge University Press, 532pp.

Lennon, G.W. (1963) The identification of weather conditions associated with the generation of major storm surges along the west coast of the British Isles. Quarterly Journal of the Royal Meteorological Society, 89(381): 381-394.

Mastenbroek, C., Burgers, G., Janssen, P.A.E.M. (1993) The dynamical coupling of a wave model and a storm surge model through the atmospheric boundary layer. Journal of Physical Oceanography, 23(8): 1856-1866.

Monbaliu, J., Padilla-Hernández, R., Hargreaves, J.C., Carretero-Albiach, J.C., Luo, W., Sclavo, M., Günther, H. (2000) The spectral wave model WAM adapted for applications with high spatial resolution. Coastal Engineering, 41(1-3): 41-62.

Osuna, P., Wolf, J. (2005) A numerical study on the effect of wave-current interaction processes in the hydrodynamics of the Irish Sea. Proceedings of the 5 th International Conference on Ocean Wave Measurement and Analysis: WAVES2005, Madrid, Spain, 10pp.

Smith, S.D., Banke, E.G. (1975) Variation of the surface drag coefficient with wind speed. Quarterly Journal of the Royal Meteorology Society, 101(429): 665-673.

Taylor, P.K., Yelland, M.J. (2001) The Dependence of Sea Surface Roughness on the Height and Steepness of the Waves. Journal of Physical Oceanography, 31(2): 572-590. 
Williams, J.A., Flather, R.A. (2000) Interfacing the operational storm surge model to a new mesoscale atmospheric model. POL Internal Document no. 127, Proudman Oceanographic Laboratory, Liverpool. 18pp.

Woodworth, P.L. and Blackman, D.L. (2002) Changes in extreme high waters at Liverpool since 1768. International Journal of Climatology. 22(6): 697-714.

Wolf, J. (2008) Coupled wave and surge modeling and implications for coastal flooding, Advances in Geosciences, 17: 1-4.

Wolf, J. (1981) Surge-tide interaction in the North Sea and River Thames, in Floods due to High Winds and Tides, edited by D.H. Peregrine, Elsevier, New York, pp. 75-94.

Wolf, J., Wakelin, S.L., Holt, J.T. (2002) A coupled model of waves and currents in the Irish Sea. Proceedings of the Twelfth (2002) International Offshore and Polar Engineering Conference, Kitakyushu, Japan, 3, 108-114.

$\mathrm{Wu}, \mathrm{J}$. (1980) Wind-stress coefficients over sea surface near neutral conditions-a revisit. Journal of Physical Oceanography, 10(5): 727-740.

Wu, J. (1982) Wind-Stress Coefficients Over Sea Surface From Breeze to Hurricane. Journal Geophysical Research, 87(C12): 9704-9706.

Zijderveld, A., Verlaan, M. (2004) Towards a new gridded bathymetry for storm surge forecasting in the North Sea. EGU $1^{\text {st }}$ General Assembly, Nice, France, 25-30 April 2004, Geophysical Research Abstracts, 6, EGU04-A-05177.

\section{Figure captions:}

Fig. 1. The model nesting for the wave simulation from the NE Atlantic model (outer boundary) to the Irish Sea model (inner square) and the current model nesting from the Atlantic Margin model (same upper and lower bounds as the NE Atlantic but with narrower width represented by the dashed lines) to the Irish Sea model (inner square).

Fig. 2. The Irish Sea model domain and the coastal tide gauges used to validate the surge elevation predicted by the modelling system, during November $1977(+)$ and January 2007 (०). The location of the WaveNet wave buoy is also shown $(\times)$.

Fig. 3. The $10 \mathrm{~m}$ wind velocity $(\mathrm{m} / \mathrm{s})$ at a) 00:00 $12^{\text {th }}$ November 1977 and b) $18: 0014^{\text {th }}$ November 1977.

Fig. 4. The $10 \mathrm{~m}$ wind velocities $(\mathrm{m} / \mathrm{s})$ during the $18^{\text {th }}$ January 2007 surge event at a) 06:00 and b) 12:00.

Fig. 5. The predicted total elevation $(\bullet)$, tuned total model elevation $(+)$ and observed total elevation (-) at a) Ifracombe and b) Malin. The linear relation to tune the model boundary conditions is given in the top left corner.

Fig. 6. The times of high water at each coastal tide gauge are depicted (by stars) during the 1977 surge event.

Fig. 7. Wave data for January 2007 collected at Liverpool Bay wave buoy (solid line) and predicted by the WAM model (stars).

Fig. 8. Wave data predicted by the WAM model in November 1977 with (dots) and without (solid line) external wave influence, at the location of the Liverpool wave buoy. 
Fig. 9. Significant wave height predicted by the WAM model in November 1977 with and without external wave influence (boundary forcing), demonstrating external swell has negligible effect in the eastern Irish Sea.

Fig. 10. Wave-age at peak surge across the Irish Sea on the $18^{\text {th }}$ January 2007.

Fig. 11. Time series of the normalised wave stress $\left(\tau_{\mathrm{w}} / \tau\right)$, top panel, the wind velocity $\left(U_{10}\right)$, middle panel, and the Charnock parameter $(\alpha)$, bottom panel, at the wave buoy location during the January 2007 surge event.

Fig. 12. Time series of the normalised wave stress $\left(\tau_{\mathrm{w}} / \tau\right)$, top panel, the wind velocity $\left(U_{10}\right)$, middle panel, and the Charnock parameter $(\alpha)$, bottom panel, at the wave buoy location during the November 1977 surge event.

Fig. 13. The wave-dependent Charnock parameter, $\alpha$, at peak surge on the $18^{\text {th }}$ January 2007.

Fig. 14. The normalised wave stress, $\tau_{w, t} / \tau_{t}$, at peak surge on the $18^{\text {th }}$ January 2007.

Fig. 15. The 1977 surge prediction using Smith and Banke (S\&B) with $U_{10}$ (blue dots) and $U_{25}$ (red dots) and Charnock's relation with constant Charnock parameters of 0.0275 (red) and 0.0144 (blue). For the Charnock set up waves have (crosses) and have not (solid line) been included with regard to wave-current interaction effects on bottom friction, wave boundary forcing has not been included. The solid black line represents the data.

Fig. 16. The 1977 surge prediction using Charnock's method with constant values of 0.0275 (red line) and 0.0144 (blue line) and a wave-dependent (black dots) value. No wave influence was included in the constant Charnock parameter simulations. External wave boundary conditions were included (black crosses) in a second wave-dependent simulation. The solid black line represents the data.

Fig. 17. Surge prediction by both the operational surge model, CS3X, (dotted line) and POLCOMS (crossed line) compared to data (solid line). No waves are included in the simulations and in both cases the Charnock parameter is taken as 0.0275 for consistency.

Fig. 18. The 2007 surge prediction using Charnock's method with constant ( $\alpha=$ 0.0275 , red and $\alpha=0.0144$, blue) and wave-dependent (black dots) Charnock parameters. For the Charnock set up waves have (dots) and have not (solid line) been included with regard to wave-current interaction effects on bottom friction, wave boundary forcing has not been included. The solid black line represents the data.

Fig. 19. The total wind-stress predicted by the Charnock method with (i) no waves and constant Charnock parameters ( $\alpha=0.0275$, dashed line and $\alpha=0.0144$, dotted line) and (ii) wave-dependent parameters (solid line), during the 1977 event.

Fig. 20. The total wind-stress predicted by the Charnock method with (i) no waves and constant Charnock parameters $(\alpha=0.0275$, dashed line and $\alpha=0.0144$, dotted line) and (ii) wave-dependent parameters (solid line), during the 2007 event.

\section{Table list:}

Table 1: The regionally ( 5 tide gauge) averaged measures of accuracy during the November 1977 storm. The model set ups are as follows: Smith and Banke (S\&B) using $U_{25}$ or $U_{10}$, Charnock's parameter $(\alpha)$ set as a constant or wavedependent (WD) value with (+W) or without (No W) wave influence on the 
bottom friction. Wave boundary forcing ( $+\mathrm{W}$ b.c.) has been included in only 1 simulation. Values in bold are the optimum values.

Table 2: The regionally (5 tide gauge) averaged measures of accuracy during the January 2007 storm. The Models set ups are as defined in the caption to Table 1 , wave boundary forcing has not been included. Values in bold are the optimum values.

Table 3: The average metric values for the two surge events considered in Tables 1 and 2. Values in bold are the optimum values. The model set ups are as defined in Table 1. 

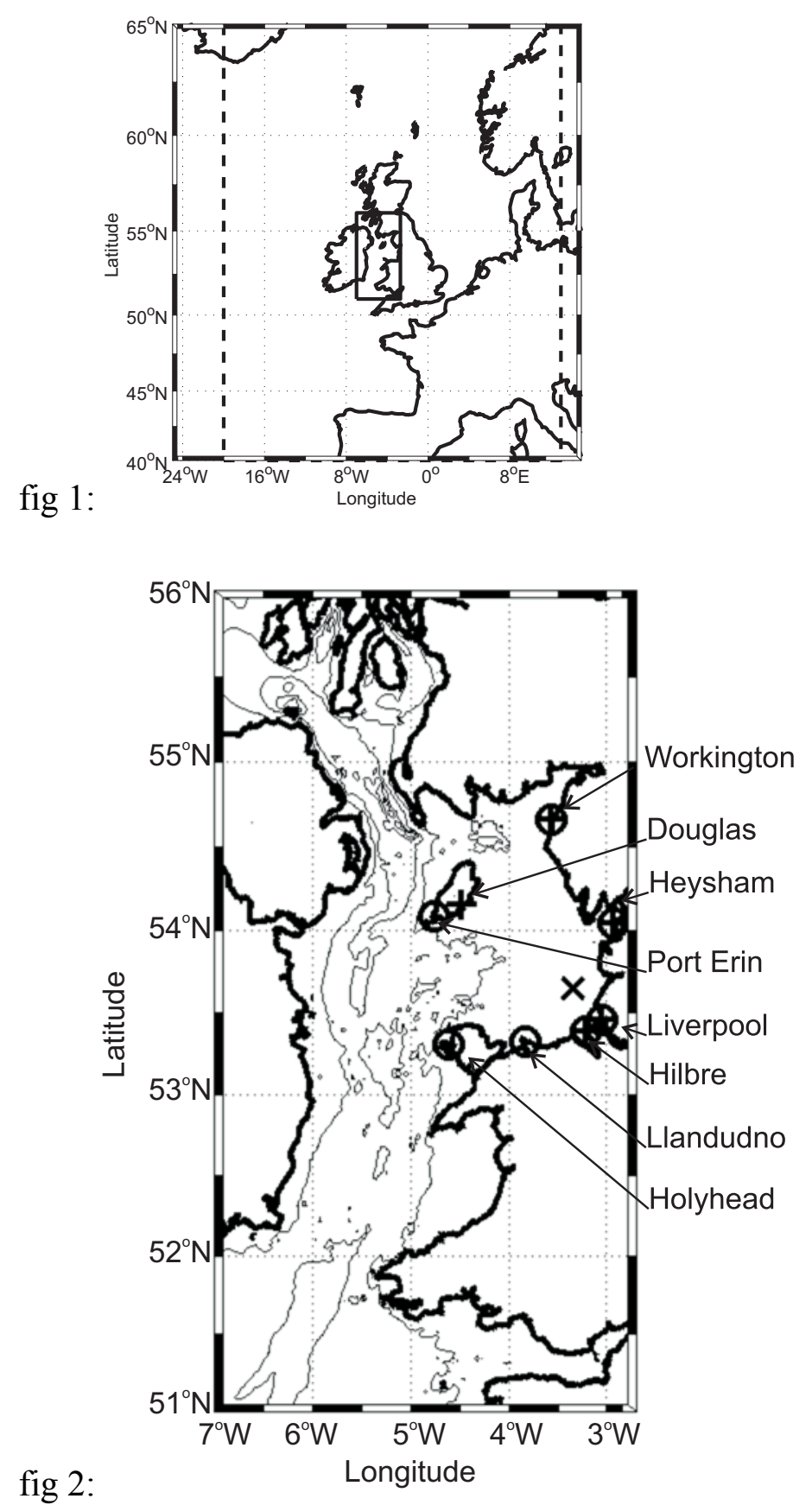

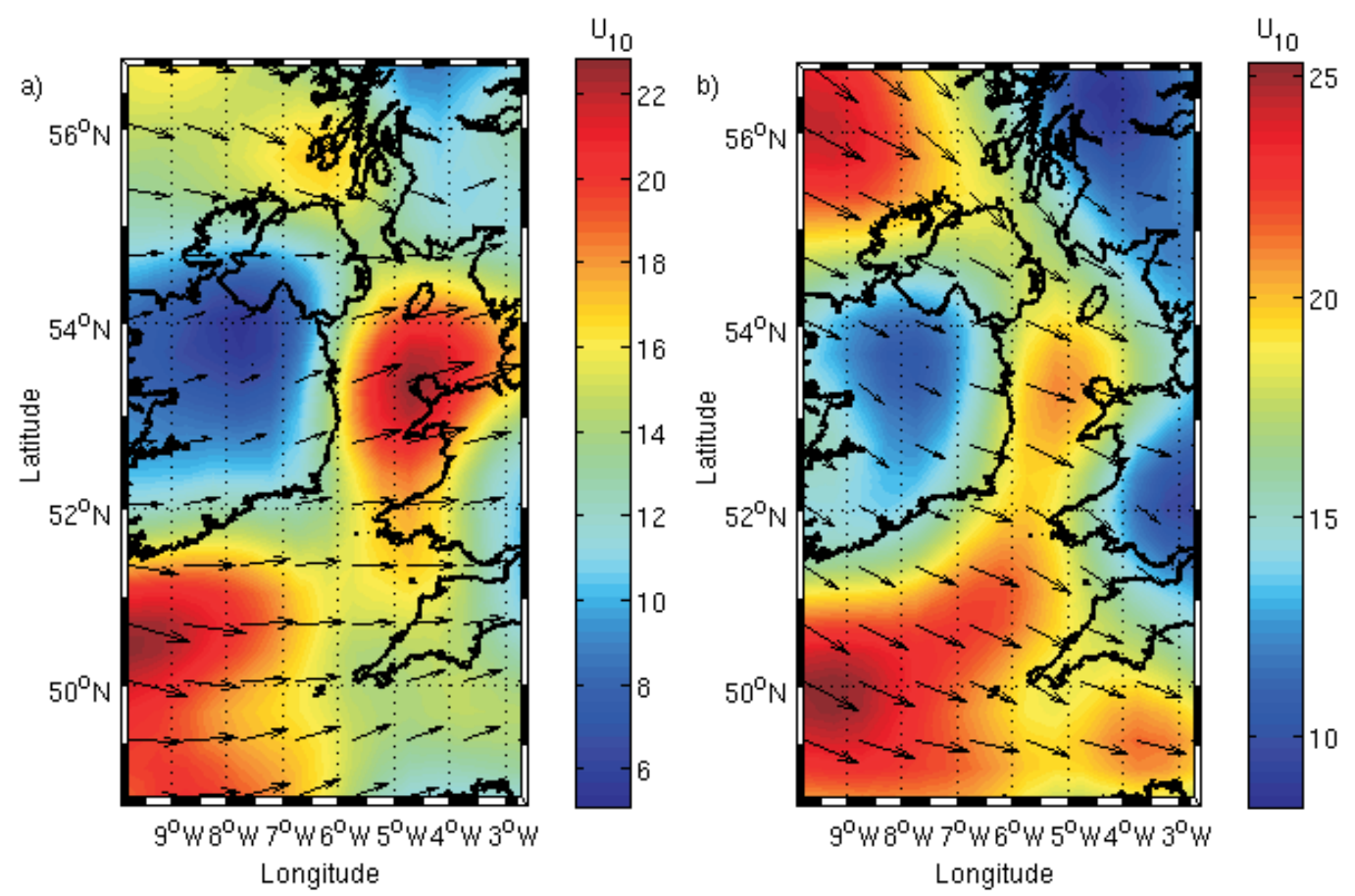

fig 3:

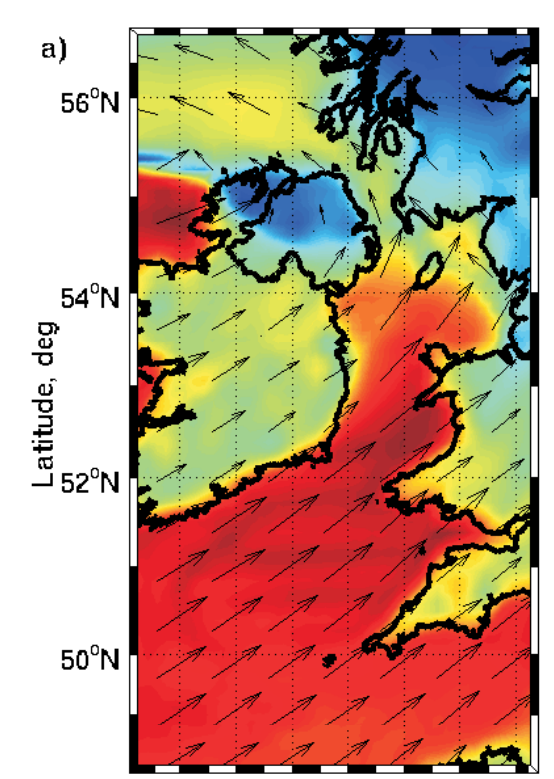

$9^{\circ} W 8^{0} W 7^{0} W 6^{\circ} W 5^{\circ} W 4^{0} W 3^{0} W$

fig 4:
$\mathrm{U}_{10}$

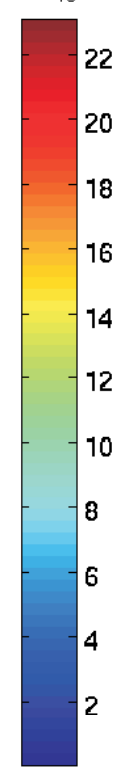

Longitude, deg

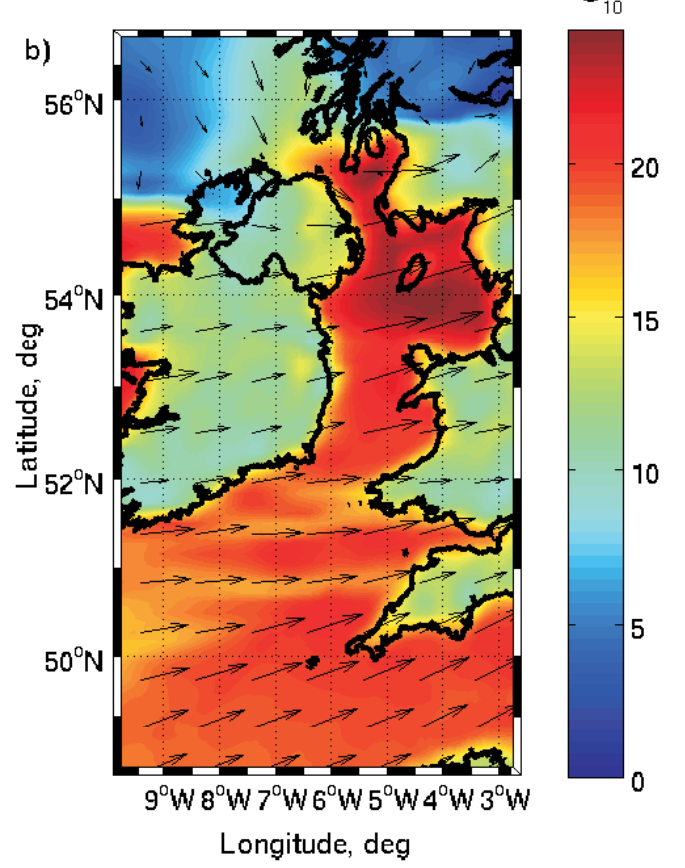


a)

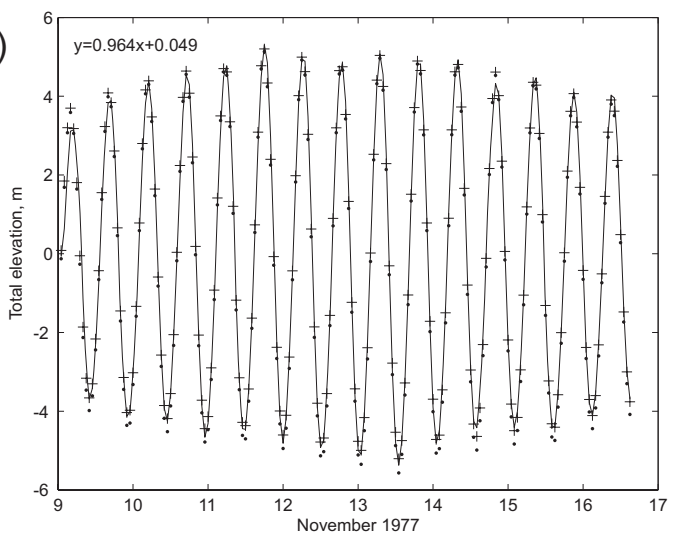

fig 5:
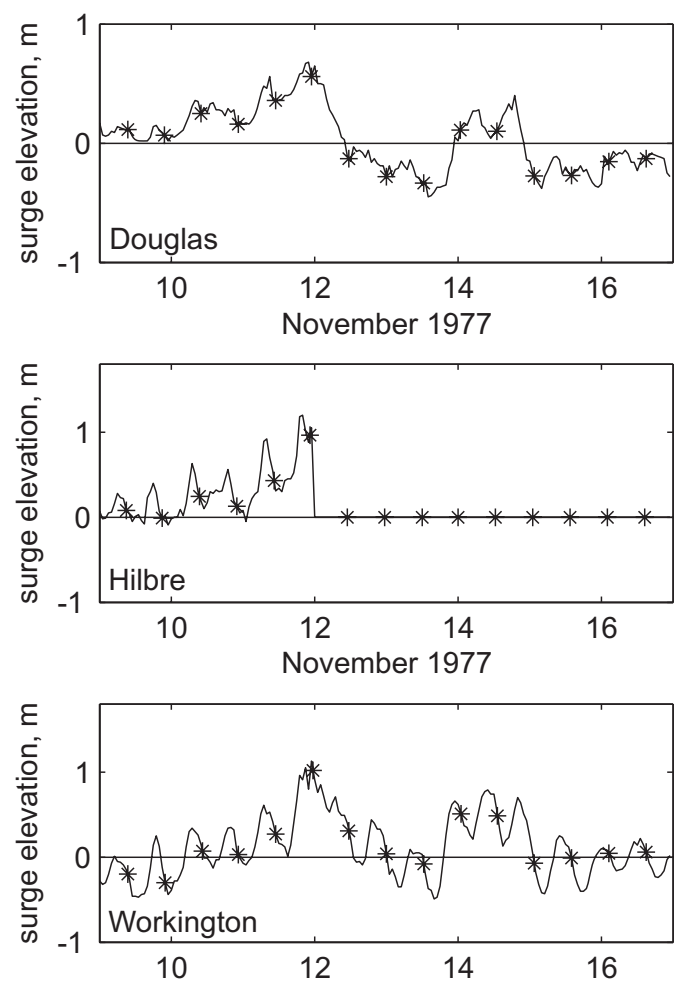

fig 6:

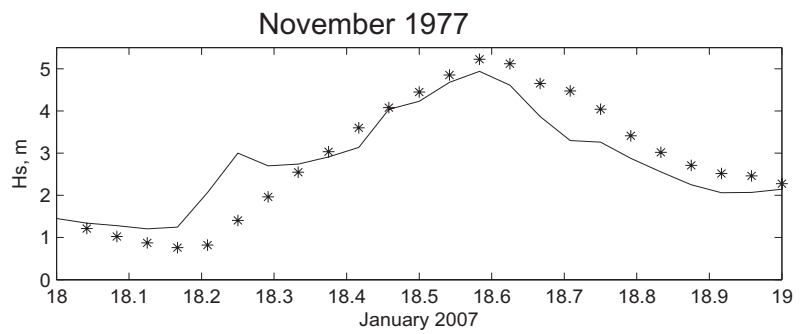

fig 7 :

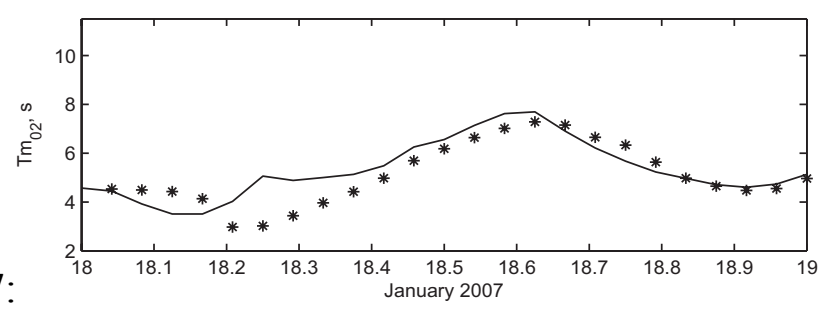

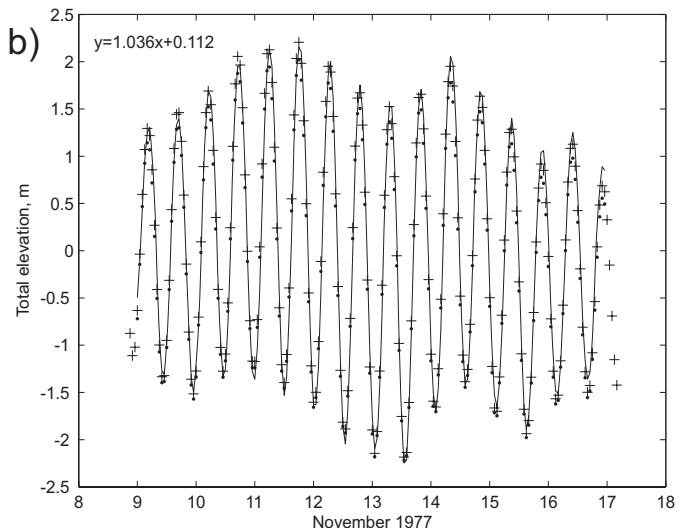
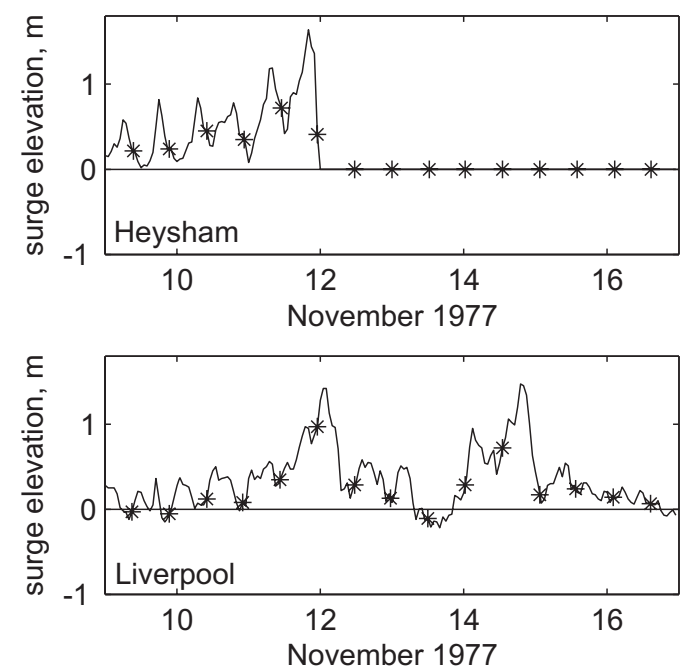

November 1977 

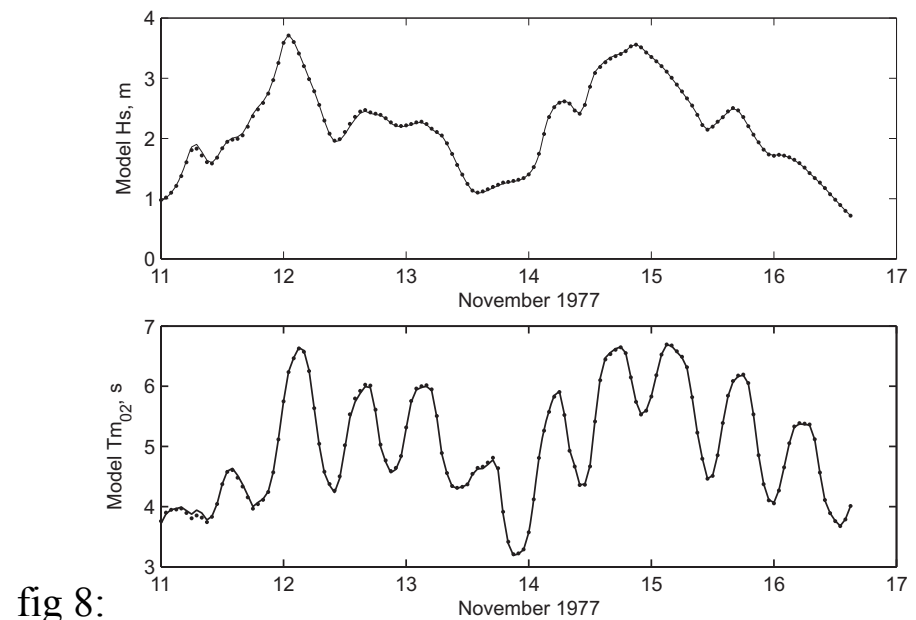

fig 8:
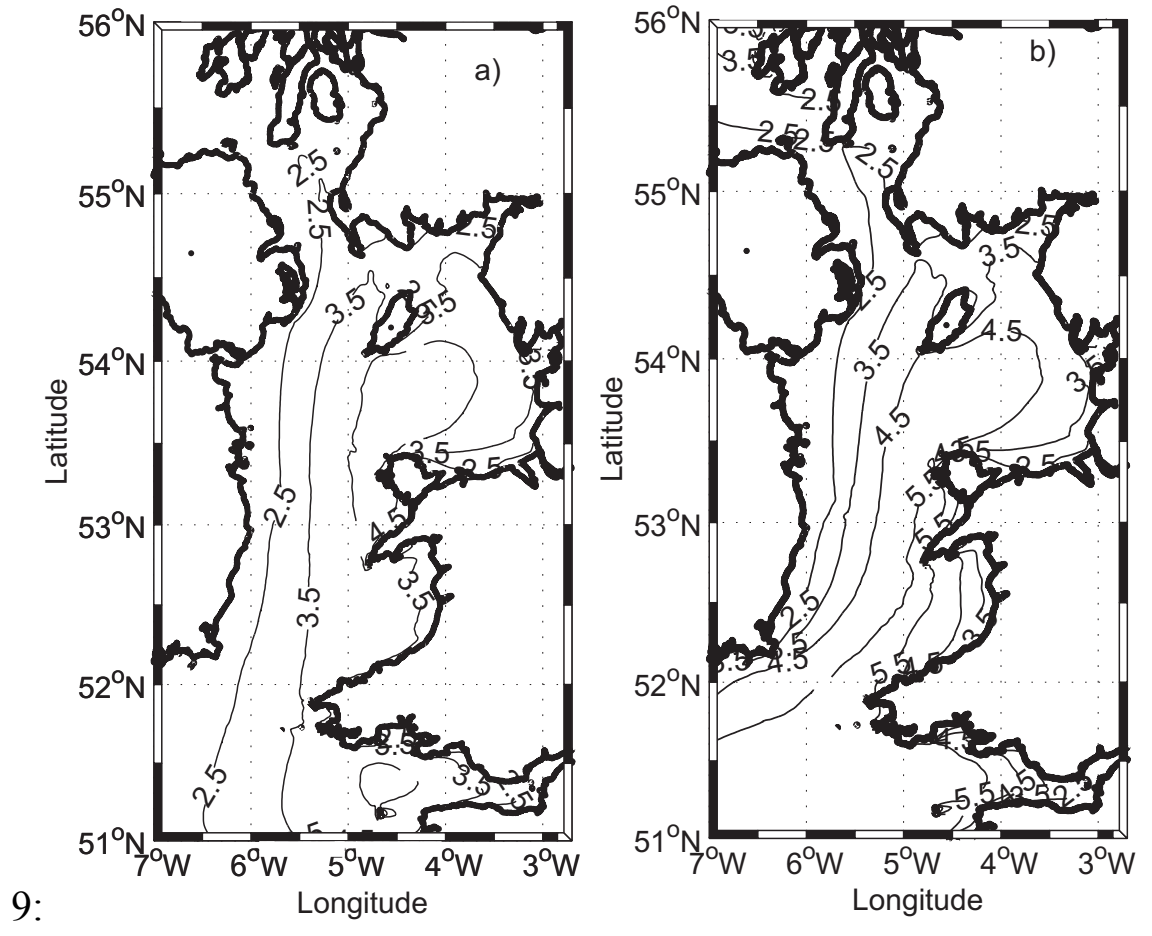

fig 9 :

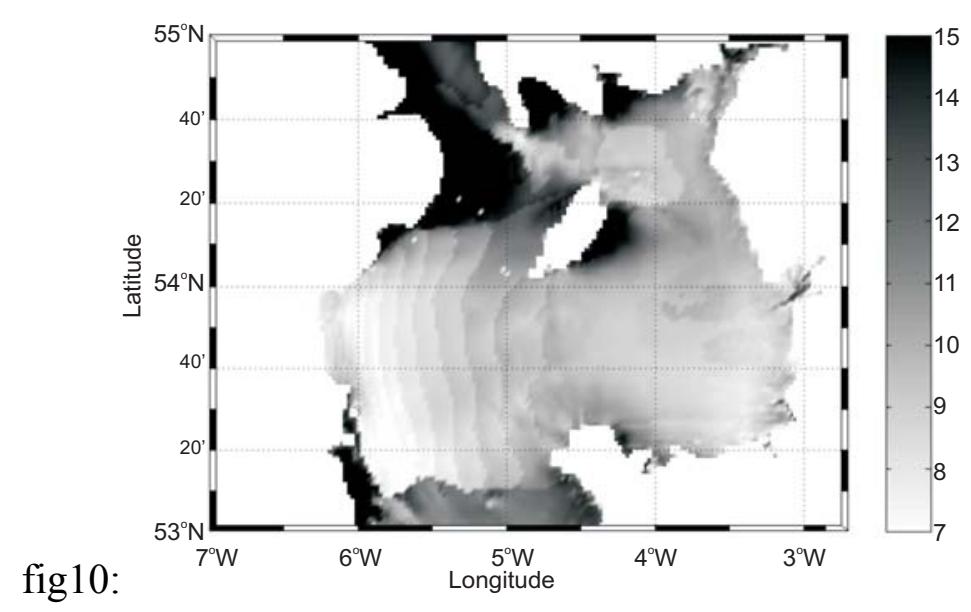



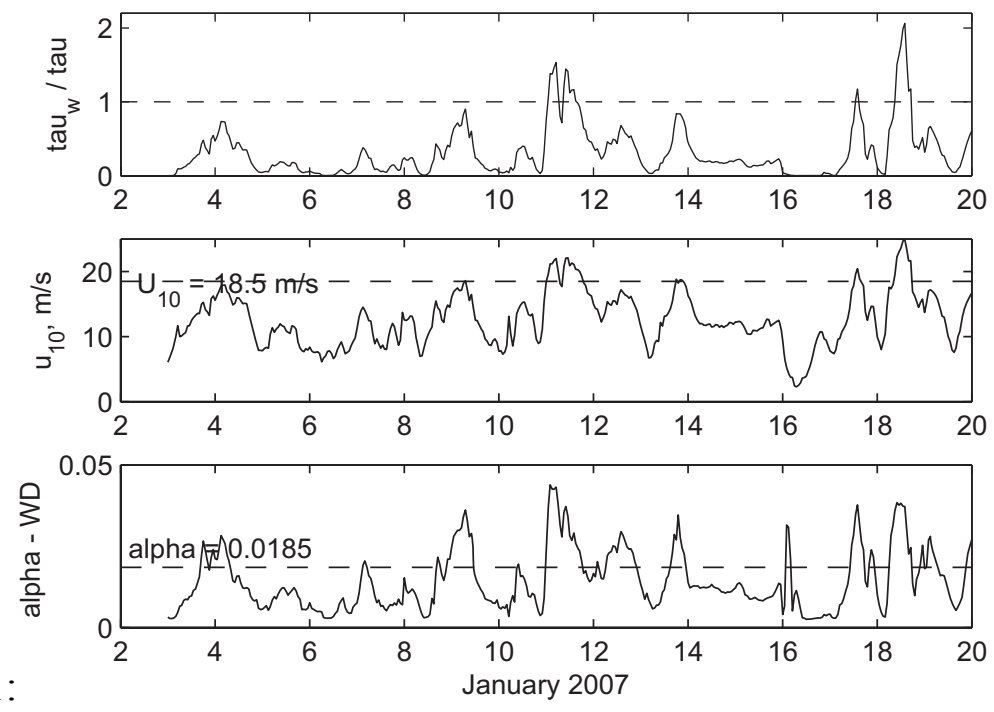

fig 11:
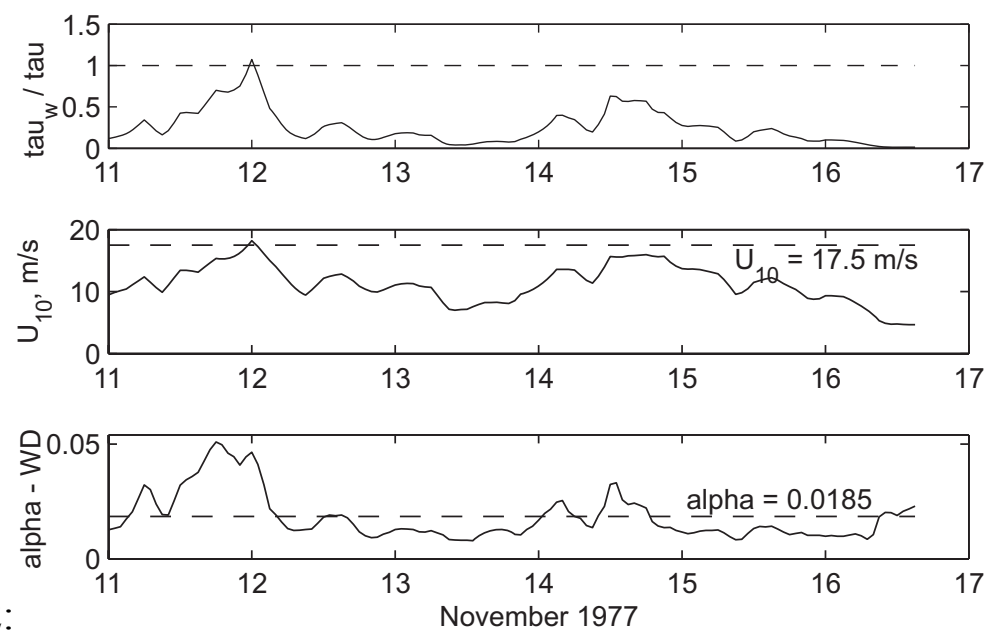

fig 12 :

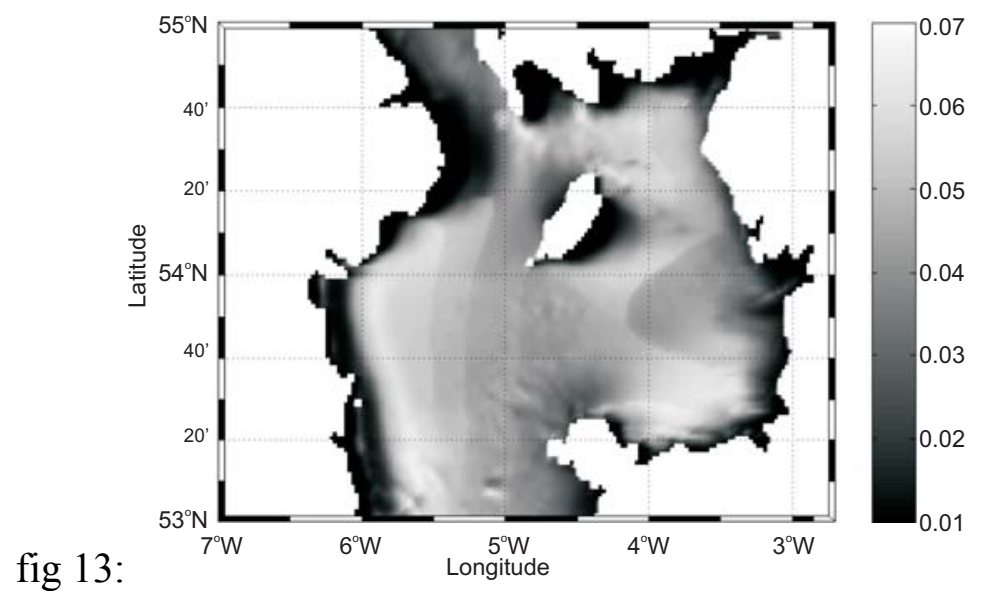



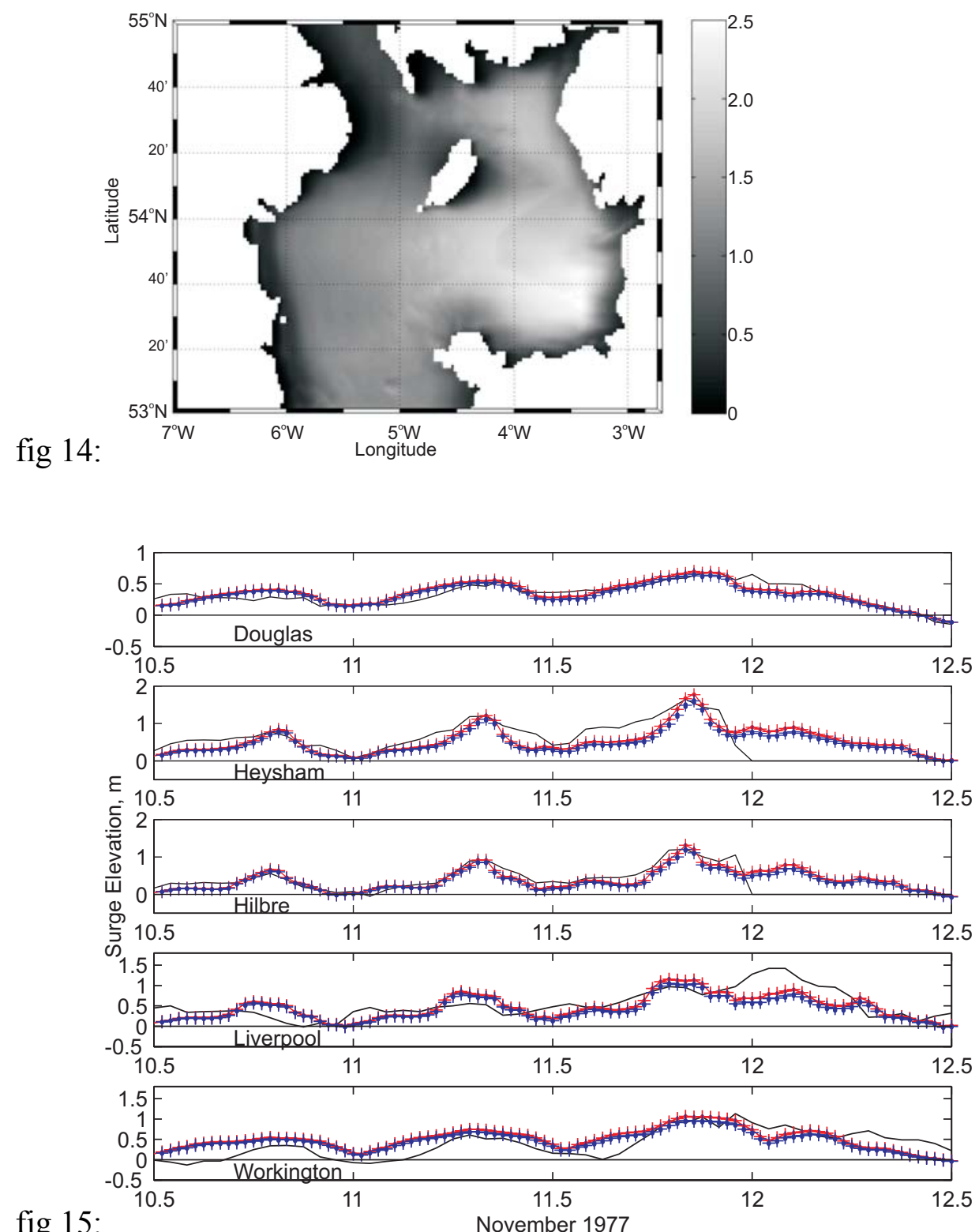

fig 15 :

November 1977 


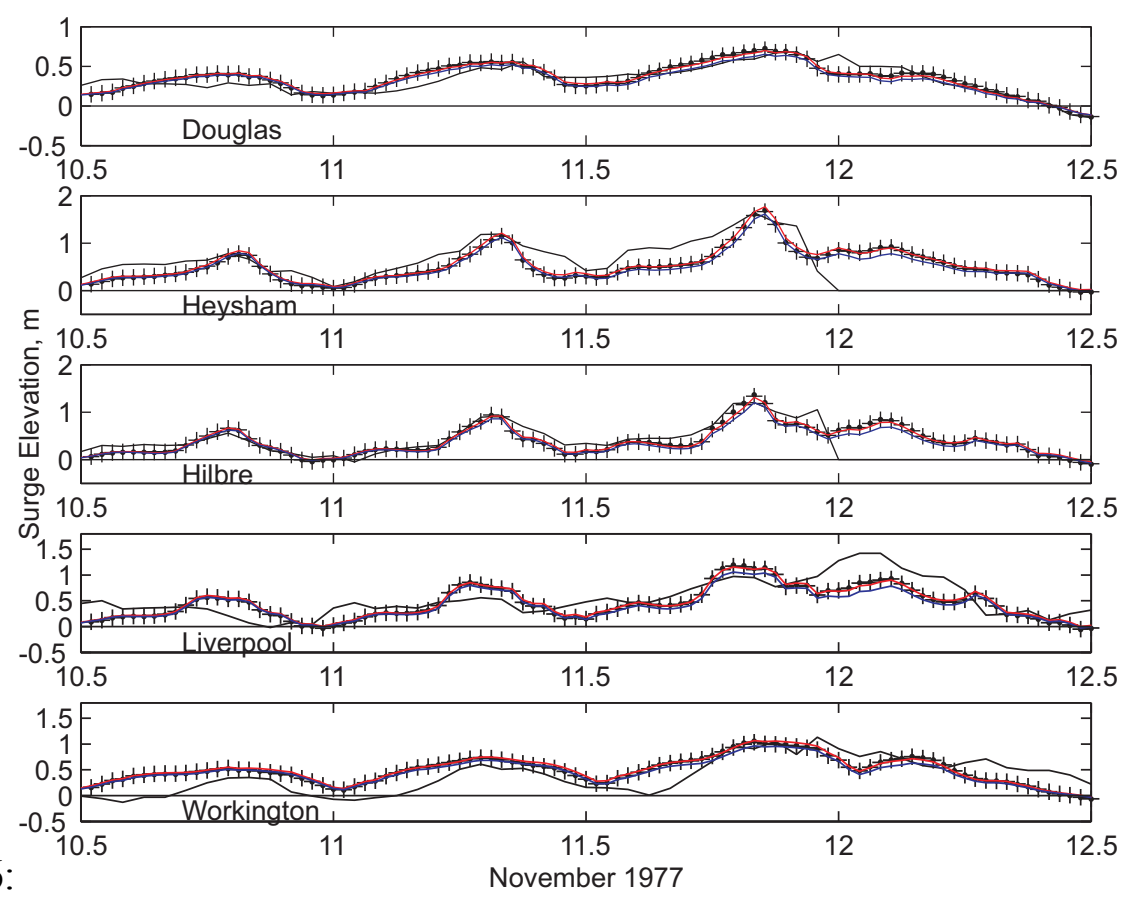

fig 16 :
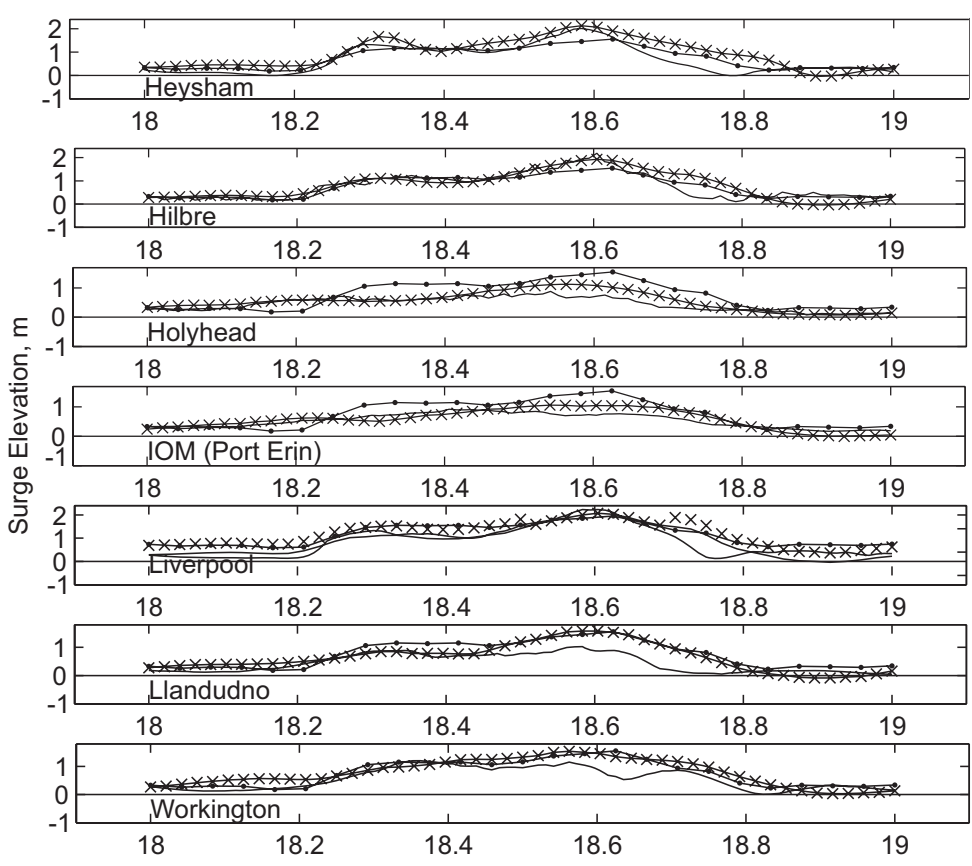

fig 17 : January 2007 


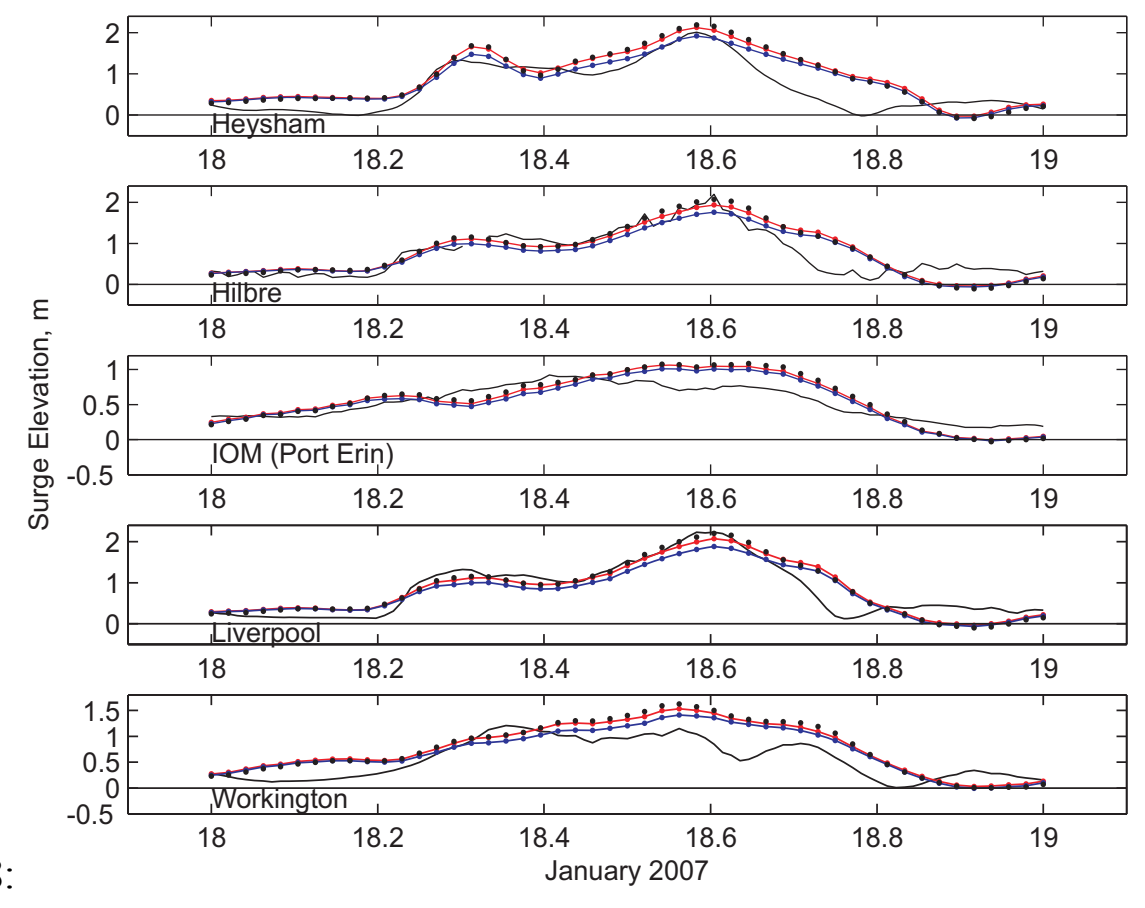

fig 18 :
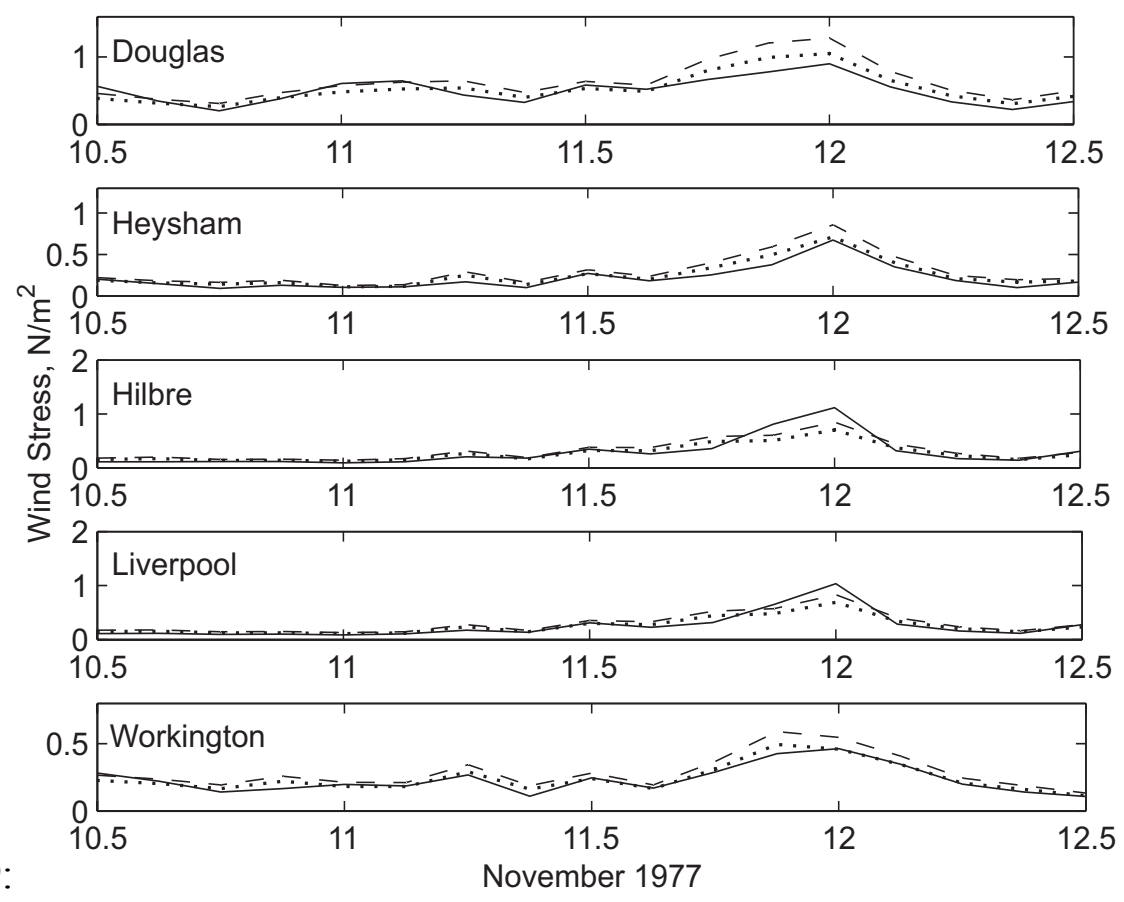

fig 19:

November 1977 

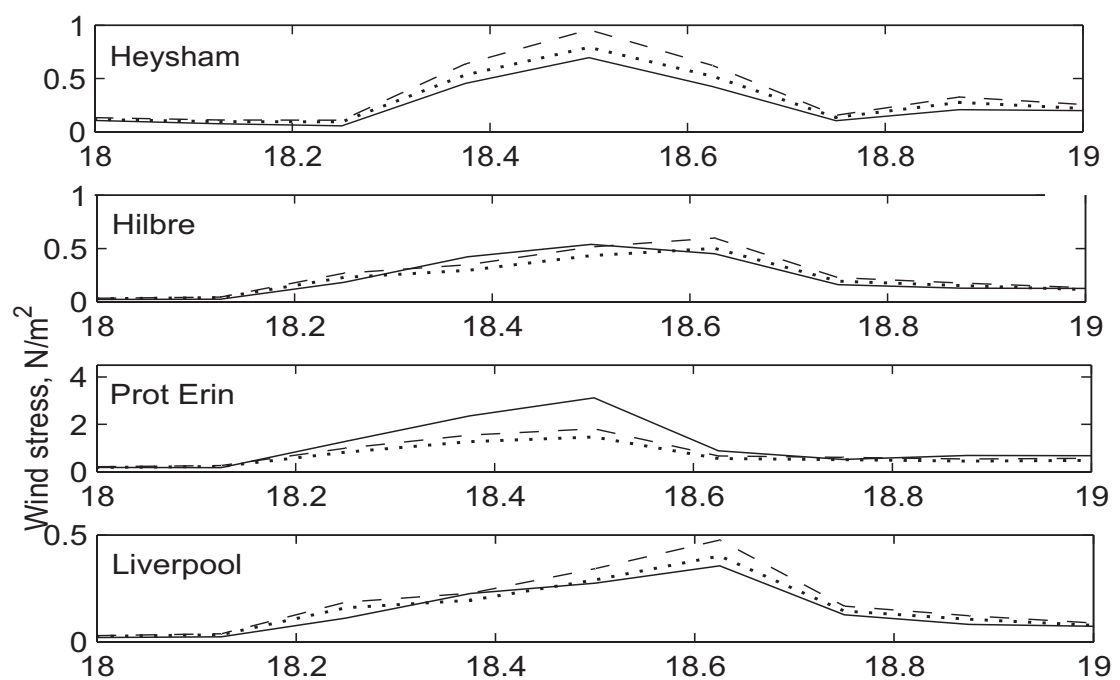

fig 20:

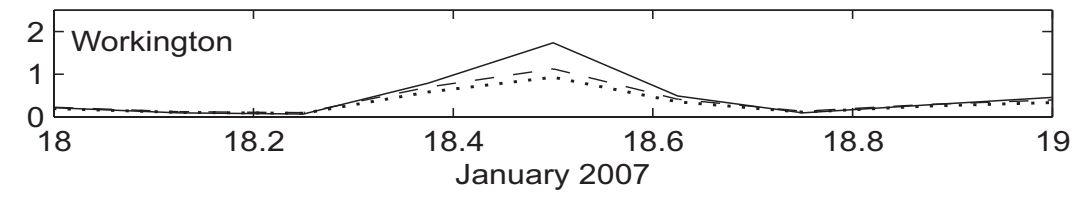

Table 1

\begin{tabular}{|c|c|c|c|c|}
\hline Model set up & $T E F, \%$ & $\begin{array}{c}P E F- \\
\text { residual, \% }\end{array}$ & $\begin{array}{c}P E F- \\
\text { skew, \% }\end{array}$ & $\begin{array}{c}\text { Peak (residual) } \\
\text { surge bias, } \mathrm{m}\end{array}$ \\
\hline S\&B, $U_{10}$ & 72.4978 & 13.2179 & 59.3802 & -0.1527 \\
\hline$\alpha=0.0144$, No W & 69.9539 & 12.2812 & 58.1769 & -0.1164 \\
\hline$\alpha=0.0144,+\mathrm{W}$ & 69.7885 & 12.3608 & 58.2294 & -0.1201 \\
\hline S\&B, $U_{25}$ & 65.2038 & 12.8641 & 55.5449 & -0.0154 \\
\hline$\alpha=0.0275$, No W & 65.1085 & 13.2301 & $\mathbf{5 5 . 3 1 7 5}$ & $-\mathbf{0 . 0 1 1 7}$ \\
\hline$\alpha=0.0275,+\mathrm{W}$ & $\mathbf{6 4 . 9 1 9 3}$ & 13.0977 & 55.3573 & -0.0150 \\
\hline$\alpha=0.0185$, No W & 67.8752 & 12.1808 & 57.1624 & -0.0793 \\
\hline$\alpha=$ WD & 66.0314 & $\mathbf{1 2 . 0 7 0 2}$ & 57.4420 & -0.0071 \\
\hline$\alpha=$ WD, +W b.c. & 66.5875 & 12.5711 & 57.9208 & -0.0298 \\
\hline
\end{tabular}

Table 2

\begin{tabular}{|c|c|c|c|c|}
\hline Model set up & TEF, \% & $\begin{array}{c}\text { PEF- } \\
\text { residual, \% }\end{array}$ & $\begin{array}{c}\text { PEF- } \\
\text { skew, \% }\end{array}$ & $\begin{array}{c}\text { Peak (residual) } \\
\text { surge bias, } \mathrm{m}\end{array}$ \\
\hline$\alpha=0.0144$, No W & $\mathbf{6 2 . 1 7 5 6}$ & 15.2196 & 29.6381 & -0.1141 \\
\hline$\alpha=0.0144,+\mathrm{W}$ & 62.1885 & 15.1223 & 29.6184 & -0.1123 \\
\hline$\alpha=0.0275$, No W & 66.4509 & 11.5661 & 27.7723 & $\mathbf{0 . 0 3 6 3}$ \\
\hline$\alpha=0.0275,+\mathrm{W}$ & 66.4920 & 11.5299 & $\mathbf{2 7 . 7 5 8 5}$ & 0.0380 \\
\hline$\alpha=0.0185$, No W & 63.2028 & 13.1338 & 28.9365 & -0.0614 \\
\hline$\alpha=$ WD & 69.0990 & $\mathbf{9 . 0 2 9 9}$ & 33.8886 & 0.1264 \\
\hline
\end{tabular}

Table 3

\begin{tabular}{|c|c|c|c|c|}
\hline Model set up & $\begin{array}{c}\text { Mean } \\
\text { TEF, \% }\end{array}$ & $\begin{array}{c}\text { Mean PEF- } \\
\text { residual, \% }\end{array}$ & $\begin{array}{c}\text { Mean PEF- } \\
\text { skew, \% }\end{array}$ & $\begin{array}{c}\text { Mean absolute peak } \\
\text { (residual) surge bias, } \mathrm{m}\end{array}$ \\
\hline$\alpha=0.0144$, No W & 66.0648 & 13.7504 & 43.9075 & 0.1153 \\
\hline$\alpha=0.0144,+\mathrm{W}$ & 65.9885 & 13.7416 & 43.9239 & 0.1162 \\
\hline$\alpha=0.0275$, No W & 65.7797 & 12.3981 & $\mathbf{4 1 . 5 4 4 9}$ & $\mathbf{0 . 0 2 4 0}$ \\
\hline$\alpha=0.0275,+\mathrm{W}$ & $\mathbf{6 5 . 7 0 5 7}$ & $\mathbf{1 2 . 3 1 3 8}$ & 41.5579 & 0.0265 \\
\hline$\alpha=0.0185$, No W & 65.5390 & 12.6573 & 43.0495 & 0.0704 \\
\hline$\alpha=$ WD & 67.5652 & 10.5501 & 45.6653 & 0.0668 \\
\hline
\end{tabular}

